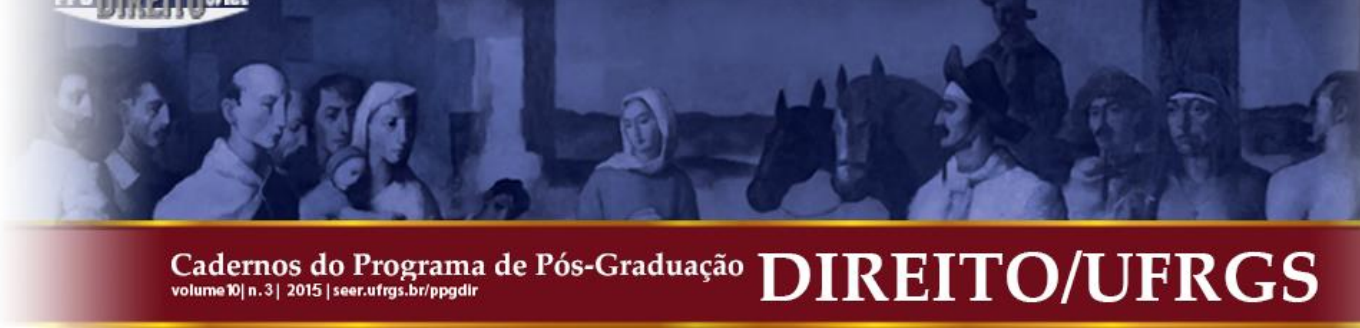

\title{
ACERTOS, ERROS E EQUÍVOCOS DE AUTOCOMPREENSÃO DA TEORIA DOS PRINCÍPIOS*
}

\author{
EINSICHTEN, IRRTÜMER UND SELBSTMISSVERSTÄNDNIS DER PRINZIPIENTHEORIE
}

\author{
INSIGHTS, ERRORS AND SELF-MISCONCEPTIONS OF THE THEORY OF PRINCIPLES
}

\author{
Ralf Poscher**
}

\begin{abstract}
RESUMO: A teoria dos princípios é multifacetada. Sua expressão inicial contém um importante argumento contra as teorias positivistas de aplicação do Direito. Como teoria do Direito, ela falha em seu esforço de reivindicar uma diferença estrutural entre regras e princípios. Ela também falha como teoria metodológica que reduz a aplicação jurídica à subsunção e à ponderação. Ela se autocompreende de forma equivocada quando concebida como dogmática especial dos direitos fundamentais. Seu aspecto mais promissor poderia ser sua contribuição para uma teoria da argumentação mais abrangente.
\end{abstract}

PALAVRAS-CHAVE: Teoria dos princípios. Acertos. Equívocos teóricos. Teoria da argumentação jurídica. Teoria da aplicação do Direito.
ZUSAMMENFASSUNG: Die Theorie der Prinzipien ist vielfältig. Ihr ursprünglicher Ausdruck enthielt ein wichtiges Argument gegen die positivistischen Theorien der Rechtsanwendung. Als Rechtstheorie scheitert sie an ihren Bemühungen einen strukturellen Unterschied zwischen Regeln und Prizipien zu erreichen. Sie verfehlt auch als methodische Theorie, die die Rechtsanwendung auf Subsumtion oder Abwägung reduziert. Sie verkennt sich selbst, wenn sie als eine spezielle Dogmatik der Grundrechte konzipiert wird. Ihr viel versprechendster Aspekt könnte ihr Beitrag zu einer umfassenderen Theorie der juristischen Argumentation sein.

SCHLÜSSELWÖRTER: Prinzipientheorie Einsichten. Theoretische Missverständnisse. Theorie der juristischen Argumentation. Theorie der Rechtsanwendung.
ABSTRACT: The theory of principles is multifaceted. Its initial expression contained an important argument against positivist theories of adjudication. As a legal theory, it fails in its effort to claim a structural difference between rules and principles. It also fails as a methodological theory that reduces adjudication to subsumption or balancing. It misunderstands itself when it is conceived as a special doctrinal theory of fundamental rights. Its most promising aspect could be its contribution to a more comprehensive theory of legal argumentation.

KEYWORDS: Theorie of principles. Insights. Theorethical misconceptions. Theory of Legal Argumentation. Theory of Adjudication.

SUMÁRIO: 1 . O ponto de partida: a crítica correta às teorias positivistas da aplicação do direito; 2. O erro de teoria do Direito: a distinção estrutural entre princípios e regras; 3. A reincidência no erro metodológico: o conceito de regra da teoria dos princípios; 4. A posição sistemática: a teoria da argumentação; 5 . O equívoco de autocompreensão: a teoria dos princípios como dogmática. Referências.

Sob o conceito de "teoria dos princípios", que sugere unidade, esconde-se um grande número de projetos talvez relacionados, mas também muito diferenciados. Sem pretensão de

\footnotetext{
* Publicação original: POSCHER, Ralf. Einsichten, Irrtürmer und Selbstmissverständnis der Prinzipientheorie. (In) SIECKMANN, Jan-R. (Org.) Die Prinzipientheorie der Grundrechte. Studien zur Grundrechtstheorie Robert Alexys. Nomos, 2007. P. 59-79. Traduzido por Pablo Castro Miozzo, doutorando em Direito pela Universidade de Freiburg (Albert-Ludwigs-Universität Freiburg), Alemanha, com autorização do autor.

${ }^{* *}$ Professor titular de Direito Público, História Constitucional e Filosofia do Direito, diretor do Departamento de Filosofia do Direito da Universidade de Freiburg (Albert-Ludwigs-Universität Freiburg), Alemanha. Possui doutorado e livre-docência (Habilitation) em Direito pela Humboldt-Universität zu Berlin, Alemanha.
} 


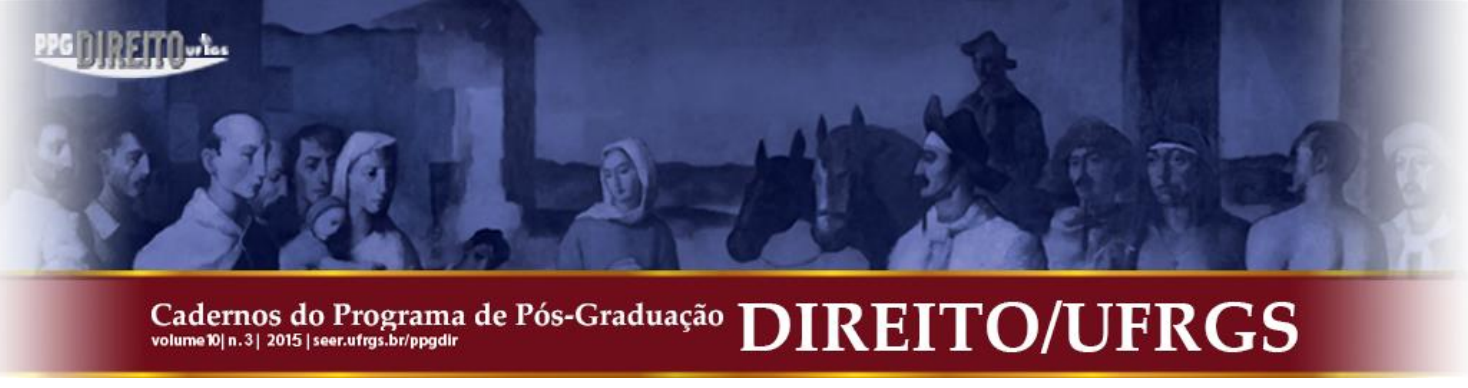

completude, em todo caso, é possível distinguir cinco diferentes aspectos da teoria dos princípios.

No contexto de discussão anglo-saxônico encontra-se a teoria dos princípios, 1) como argumento de princípio, no nível das teorias estruturais do Direito, que pergunta pelas características gerais de ordens jurídicas e pelas suas relações com outros fenômenos normativos, em especial, o ético-moral ou também o fenômeno do político. ${ }^{1}$ 2) Como projeto lógico-jurídico ou teorético-jurídico representa a teoria dos princípios não uma teoria sobre a estrutura de uma ordem normativa - da ordem jurídica - mas sim uma teoria sobre a estrutura lógica de normas individuais. A este contexto pertence a tese de que o inventário no espaço do normativo pode ser categoricamente classificado em princípios ou regras. ${ }^{2}$ 3) Em conexão com essa tese, mas, entretanto, dela carente de diferenciação, aparece a teoria dos princípios também como teoria metodológico-jurídica de uma diferença categórica entre dois modos de aplicação do Direito: nomeadamente a aplicação do Direito por meio da subsunção no caso das regras e por meio da ponderação no caso dos princípios. ${ }^{3}$ 4) Além disto, há um projeto teorético-argumentativo, que investiga o significado dos princípios no espaço de fundamentações jurídicas. "Princípios são argumentos", diz-se com frequência entre os defensores da teoria dos princípios. $^{4}$ A preocupação de Esser ${ }^{5}$ também pode ser provavelmente mais bem situada no espaço de um projeto desse tipo. 5) Por fim, vincula-se com o conceito de teoria dos princípios uma tese de dogmática dos direitos fundamentais. De acordo com tal tese, os direitos fundamentais são mandamentos de optimização e questões sobre direitos fundamentais só podem ser respondidas por meio de uma ponderação de princípios colidentes. ${ }^{6}$

As reflexões que seguem pretendem demostrar que a teoria dos princípios trouxe, em sua forma original, uma contribuição restaurativa, porém importante, para uma teoria da

1 RAZ, J. Legal principles and the Limits of the Law. The Yale Law Journal 81, 1972. p. 823-854; DWORKIN, R. Bürgerrechte ernstgenommen. Frankfurt: Suhrkamp, 1984. p. 55, 102-104; HART, H.L.A. Concept of Law. 2. ed. Oxford: Oxford University Press, 1994. p. 155-180, 268-272; a recepção alemã também aponta para esta relação teorético-estrutural, Cf. ALEXY, R. Begriff und Geltung des Rechts. Freiburg: Alber, 1992. p. 117-129.

2 ALEXY, R. Theorie der Grundrechte. Frankfurt: Suhrkamp, 1986. p. 72.

3 SIECKMANN, J.-R. Regelmodelle und Prinzipienmodelle des Rechtssystems. Baden-Baden: Nomos, 1990., p. 18 e ss, também ALEXY, R. On Balancing and Subsumption. Ratio Juris 16, 2003. p. 433; Cf. também LARENZ, K. Methodenlehre der Rechtswissenschaft. 6. ed. Berlin: Springer, 1991. p. 472-482.

4 SIECKMANN, J.-R. Rechtssystem und praktische Vernunft, ARSP 78: 1992. p. 154-151; do mesmo autor, Modelle des Eigentumsschutzes. Baden-Baden: Nomos, 1998. p. 38.

5 ESSER, J. Grundsatz und Norm in der richterlichen Form des Privatrechts. 4. ed. Tübingen: Mohr Siebeck, 1990.

6 ALEXY. Theorie der Grundrechte. p. 71-77.

Cadernos do Programa de Pós-Graduação em Direito PPGDir./UFRGS | Edição Digital | Porto Alegre | Volume X | Número 3 | 2015 | P. 3 - 38 


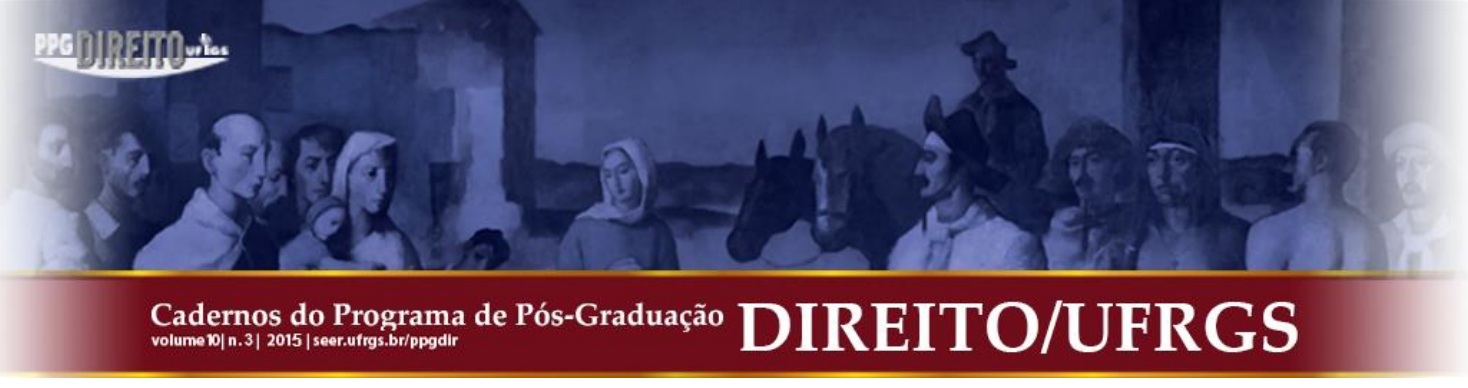

aplicação do Direito; que em sua hipertrofia metodológica e teórico-normativa, no entanto, se baseia em erros e que, enquanto uma teoria dogmática dos direitos fundamentais, ela se autocompreende de forma equivocada. Com isto, as reflexões farão sempre referência à teoria dos princípios como teoria dos direitos fundamentais, não apenas porque neste âmbito a sua recepção é mais amplamente avançada ${ }^{7}$, mas também porque ela é considerada internamente (no interior da escola) um caso de aplicação paradigmático.

\section{O PONTO DE PARTIDA: A CRÍTICA CORRETA ÀS TEORIAS POSITIVISTAS DA APLICAÇÃO DO DIREITO}

Em sua gênese, o pensamento a partir de princípios reagiu a um campo de debate que se desenvolveu, pelo menos na discussão alemã e na anglo-saxônica, com conexões individuais, mas também, em um grau surpreendente, de forma paralela e independente. Nesse e naquele lado do Atlântico a teoria dos princípios teve sua origem em um desenvolvimento apenas temporalmente deslocado no clima teórico-jurídico global. A precedência coube em dado momento à discussão de língua alemã. Em reação ao endurecimento, mas principalmente a estilizações da jurisprudência dos conceitos e em sintonia com as ciências sociais em desenvolvimento enquanto disciplinas, formou-se aproximadamente no final do séc. XIX uma crítica radical às ideias metodológicas tradicionais. ${ }^{8}$ A ideia do Juiz como um "autômato da subsunção", com quem a reivindicação burguesa ao Estado-justiça fora controlada ${ }^{9}$, foi levada metodicamente a sério e "desmascarada". A crítica intensificou-se até chegar ao programa cético-jurídico da escola do

\footnotetext{
7 Ver sobre isso as traduções da "Theorie der Grundrechte" de Alexy para o espanhol por VALDEZ, E. G. Teoría de los derechos fundamentales. 3. ed. 2001. ou para o inglês por RIVERS, J. A theory of Constitutional Rights. 2002; bem como os respectivos trabalhos de seus alunos, que se concentram essencialmente na dogmática dos direitos fundamentais, JANSEN, N. Die Abwägung von Grundrechten. (In) Der Staat 36. 1997. p. 25-54; SIECKMANN. Rechtssystem und praktische Vernunft. ARSP 78. 1992. p. 154-151; BOROWSKI, Martin. Grundrechte als Prinzipien. 2. Auflage. Baden-Baden: Nomos, 1998.; do mesmo autor, Prinzipien als Grundrechtsnormen. ZöR 53. 1998. p. 307-335; TEIFKE, N. Flexibilität der Menschenwürde? In. C. Bäcker/S. Baufeld (Org.), Objektivität und Flexibilität im Recht. ARSP Beiheft 10: 2005. p. 142-156; BOROWSKI, M. Die Glaubes-und Geewissenfreiheit des Grundgesetzes. Tübingen: Mohr Siebeck, 2006.

8 JHERING, R. Der Kampf ums Recht. Wien: Manz, 1872.; ADICKES, F. Zur Lehre von den Rechtsquellen insbesondere über die Vernunft und die Natur der sache als Rechtsquellen und über das Gewohnheitsrecht. Kassel: Wigand, 1872. p. 9- 15; JHERING, R. Scherz und Ernst in der Jurisprudenz. Leipzig: Breitkopf \& Härtel, 1884.; BÜLOW, O. Gesetz und Richteramt. Berlin: Berliner Wissenschaftsverlag, 1885.; EHRLICH, E. Über Lücken im Rechte. (1888), in: EHRLICH, E. Recht und Leben. Berlin: Duncker und Humblot, 1967. p. 30-169.

9 OGOREK, R. Richterkönig oder Subsumtionsautomat? Frankfurt: Klostermann, 1986. p. 292-325.
}

Cadernos do Programa de Pós-Graduação em Direito PPGDir./UFRGS | Edição Digital | Porto Alegre | Volume X | Número 3 | 2015 | P. 3 - 38 


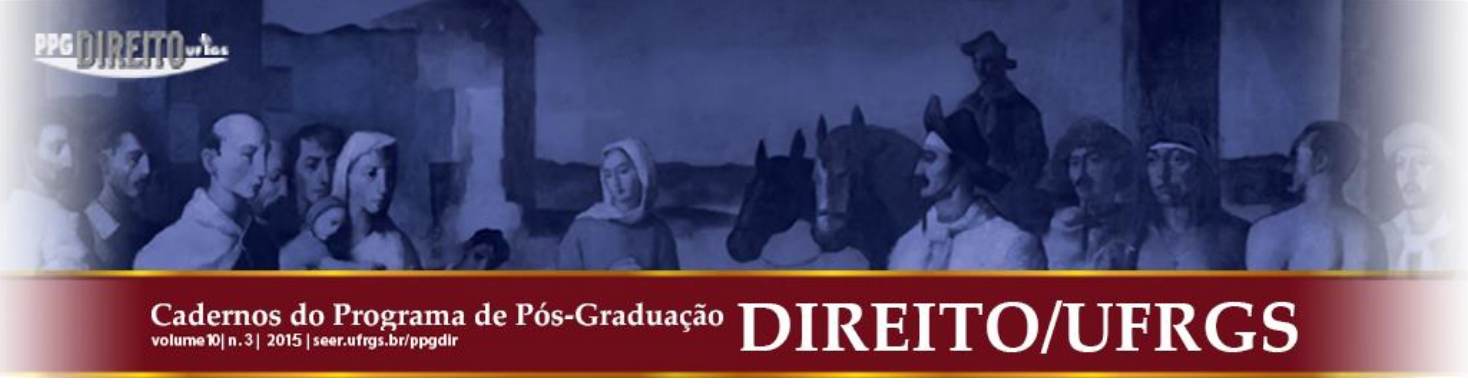

Direito livre, que rejeitava amplamente a força de determinação do Direito e desenvolveu alternativas, geralmente programas de aplicação do Direito psicologizantes ${ }^{10} \mathrm{ou}$ com base nas ciências sociais ${ }^{11} \cdot{ }^{12}$ Além de François Geny ${ }^{13}$, Rudolf Jhering ${ }^{14}$ é visto como precursor e Eugen Ehrlich ${ }^{15}$ como protagonista escola do Direito livre, e todos foram fontes essenciais de inspiração europeia para o desenvolvimento paralelo do realismo jurídico americano.

O realismo jurídico americano defendia, na essência, um programa similar ao da Escola do Direito livre e reagia, como ela, à pretensão metodológica hipertrofiada de uma compreensão do Direito a partir de conceitos jurídicos, que, sob a bandeira do formalismo, dominava a teoria e a prática nos EUA. ${ }^{16}$ A reação americana também se ligava à indeterminação do Direito e se transformou, na modalidade radical do realismo jurídico, num amplo ceticismo jurídico. ${ }^{17}$

10 EHRLICH, E. Freie Rechtsfindung und freie Rechtswissenschaft. Leipzig: C. L. Hirschfeld, 1903.; EHRLICH, E. Grundlegung der Soziologie des Rechts. München und Leipzig: Duncker und Humblot, 1913; FUCHS, E. Was will die Freirechtsschule?, (1929), (In) FUCHS, E. Gerechtigkeitswissenschaft. Ausgewählte Schriften zur Rechtslehre. Karlsruhe: CF Müller, 1965. p. 21-63; KANTOROWICZ, H. Rechtswissenschaft und Soziologie. (In) KANTOROWICZ, H. Ausgewählte Schriften zur Wissenschaftslehre. Karlsruhe: Müller, 1962. p. $117-144$.

11 FLAVIUS, G. (H. Kantorowicz). Der Kampf um die Rechtswissenschaft. Heidelberg: Carl Winters Universitätbuchhandlung, 1906. p. 16-19; ISAY, H. Rechtsnorm und Entscheidung. Aalen: Scientia, 1929. p. 85120; para maiores detalhes sobre a escola do Direito livre, ver GFINGEL, A./MOLNAU, K. A. (Org.), Gesetzesbindung und Richterfreiheit. Freiburg: Haufe-Lexware, 1992.

12 Para abordagens correspondentes de caráter sociológico ou psicológico no âmbito do realismo jurídico americano, ver LEITER, B. American Legal Realism. (In) EDMUNDSON, W. / GOLDING, M. (Org.) The Blackwell Guide to Philosophy of Law and Legal Theory. Malden: Wiley-Blackwell, 2003. p. 54-56.

13 GENY, F. Méthode d' interpretation et sources du droit privé positif. Lausanne: F. Pichon et Durand-Auzias, 1899.

14 Sobre a influência de Jhering no desenvolvimento teórico americano ver. SUMMERS, R. S. Rudolf von Jhering's Influence on American Legal Theory, in: BEHRENDS, O. (Org.), Jherings Rechtsdenken. Göttingen: Vandenhoeck \& Ruprecht, 1996. p. 61-76; DUXBURY, N. Jhering's Philosophy of Authority. Oxford Journal of Legal Studies, 2007.

15 Assim, POUND, R. Enforcement of Law. Washington: Green Bag, 1908. p. 401-406: "we have a great deal of freie Rechtsfindung in America, while disclaiming it in theory"; em particular sobre a recepção americana, NELKEN, D. Pound and Ehrlich on the Living Law. (In) Rechtstheorie: 1986. p. 175-187; HERGET, J. E; WALLACE, S. The German Free Law Movement as the Source of American Legal Realism. Va. L. Rev. 73: 1987. p. 399-440.

16 Para o desenvolvimento teórico americano ver DUXBURY, N. Patterns of American Jurisprudence. Oxford: Oxford University Press: 1995. p. 9-64.

17 Sobre isso, POUND, R. Law in Books and Law in Action. Am. L. Rev. 44: 1910.; POUND, R. An Introduction to the Philosphy of Law. 24. ed. Cumberland, RI: Yale University Press. 1982. p. 23 e ss.; LLEWELLYN, K. N. A Realistic Jurisprudence - The Next Step. (In) Columbia Law Review 30: 1930. p. 431465; FRANK, J. Law and the Modern Mind. New York: Brentanos, 1930.; acerca da tese da indeterminação metódica como fundamento do realismo jurídico americano, LEITER. American Legal Realism. (In) W. Edmundson; M. Golding (Hg.), The Blackwell Guide to Philosophy of Law and Legal Theory. Malden: WileyBlackwell, 2003.p. 51 e ss. 


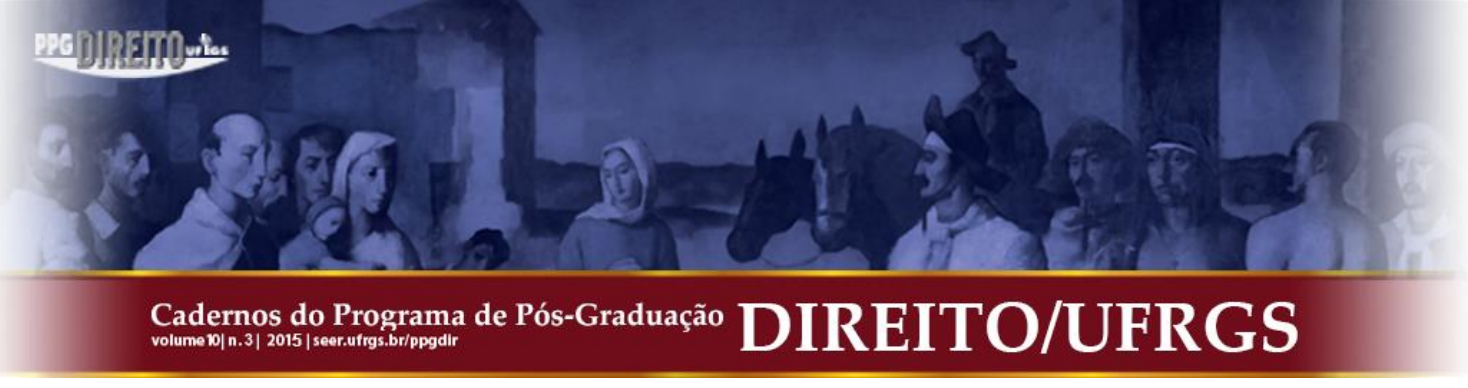

foram ocultados, ${ }^{24}$ mas que permaneceram na prática incontestados pelo positivismo, também teoricamente no lugar que lhes era de direito. É mérito duradouro da teoria dos princípios ter insistido na seriedade e na autonomia da controvérsia jurídica com referência ao papel dos princípios jurídicos na aplicação do Direito e ter rejeitado a referência obrigatória ao autoengano $^{25}$ coletivo da prática jurídica.

A ênfase no significado dos princípios para aplicação do Direito mirava, na variante anglo-saxônica, na compreensão até então ligada ao positivismo acerca da relação entre Direito e Moral. A necessidade de se recorrer aos princípios no processo de aplicação do Direito que, em todo caso, em parte não eram explicitamente codificados, era considerada por Dworkin essencialmente como moeda de troca contra a tese da separação, que negava qualquer relação entre Direito e Moral. De que origem deveriam ser os princípios invocados, uma vez que não eram codificados, senão moral no sentido amplo? ${ }^{26}$

O positivismo reagiu a essa objeção principalmente com uma ampla gama de estratégias inclusivas. ${ }^{27}$ Estas estratégias, que reconhecem fundamentalmente a objeção de Dworkin, fazem a disputa em torno da tese da separação parecer, ao menos neste ponto, desnecessária, como se nela se tratasse meramente da questão sobre se os empréstimos que a aplicação do Direito faz junto à moral cotidiana ou à filosofia moral, podem ser reconduzidos a um fundamento compreensível explícita ou implicitamente, direta ou indutivamente a partir do Direito legislado; ou sobre se tal dedução, ao menos em alguns casos, não é possível. Que tais empréstimos ocorrem, como os empréstimos que o Direito faz junto à matemática ${ }^{28}$ no direito financeiro ou junto à cronometria no cálculo de prazos ou de velocidade, não é mais discutido.

compilação enciclopédica mais recente dos princípios da Common Law: BAYLES, M. D. Principles of Law. Dordrecht: Reidel, 1987.

24 Para este desenvolvimento PASCUA, J. A. R. Die Grundlage der rechtlichen Geltung von Prinzipien (In): ORSI, G. Prinzipien des Rechts. Frankfurt: Peterlang, 1996. p. 11-13

25 HECK. Das Problem der Rechtsgewinnung, p. 17; KELSEN. Juristischer Formalismus und Reine Rechtslehre. 1723 (1726); KELSEN. Reine Rechtslehre. p. 350 e ss.; HART. The Concept of Law. p. 176-189.

26 Um esboço curto, porém interessante, acerca da história da posição normativa dos princípios jurídicos na codificação romana desde a decadência do Direito natural, encontra-se em PASCUA. Die Grundlage der rechtlichen Geltung von Prinzipien. p. 11-13. O movimento crítico de rejeição do direito natural mostra-se contrário à referência a "princípios jurídicos naturais" na determinação sobre o preenchimento de lacunas legais, primeiramente em alusões ambivalentes aos "princípios jurídicos gerais", mas também, em seguida, em prescrições conscientemente positivistas sobre os "princípios gerais do Direito vigente".

27 Uma visão geral das estratégias é oferecida respectivamente por SIECKMANN. Regelmodelle und Prinzipienmodelle des Rechtssystems. p. 178-198; COLEMAN, J L. The Practice of Principle. Oxford: Oxford University Press, 2001. p. 103-119, ambos com referências adicionais.

28 Para tal comparação, ver já KANTOROWICZ. Der Begriff des Rechts. Göttingen: Vandenhoeck \& Ruprecht, 1939. p. 58 e ss.

Cadernos do Programa de Pós-Graduação em Direito PPGDir./UFRGS | Edição Digital | Porto Alegre | Volume X | Número 3 | 2015 | P. 3 - 38 


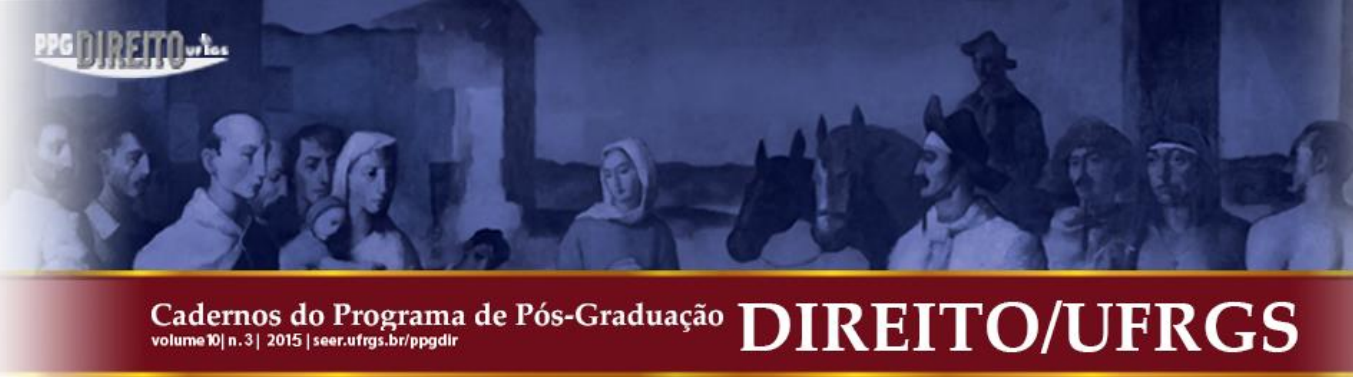

Trata-se a este respeito, de qualquer forma, de parâmetros jurídicos, no sentido de que as normas morais não podem simplesmente ser contrapostas a normas jurídicas com força derrogatória, mas apenas podem servir de recurso no âmbito da aplicação do Direito quando se encaixam no Direito legislado e forem a ele adaptadas, conforme também acentuou Dworkin com da dimensão de "ajuste" ("fit"). ${ }^{29}$ Neste sentido o Tribunal Constitucional Federal faz uso da formatação dogmática da garantia dignidade humana, qual seja, a fórmulaobjeto $^{30}$, que é subjacente a uma formulação do imperativo categórico de Kant. Entretanto, tal formatação nem receberia com isso inteiramente a filosofia moral de Kant, nem tampouco poderia fazer uso de partes de sua filosofia, se a Constituição, no art.1, inciso 1 da Lei Fundamental, não lhe desse razão para isso. Assim, a ideia de uma proteção elevada da dignidade humana em comparação com outros bens, como a vida, pode não ser compreensível do ponto de vista de uma ética consequencialista. No entanto, ainda que uma correspondente teoria se mostrasse como filosoficamente superior, uma interpretação da Lei Fundamental deveria oferecer um esboço de dignidade humana que a ela se contrapõe. A aplicação jurídica não recorre simplesmente a normas morais, mas desenvolve padrões jurídicos próprios com recurso a normas extrajurídicas. Embora estes padrões se apoiem em conceitos morais e filosóficos e a eles possam se assemelhar, eles são genuinamente jurídicos. ${ }^{31}$ É justamente uma tarefa da dogmática adaptar conceitos de outras disciplinas, inclusive da filosofia moral, às especificidades de um sistema jurídico e à sua história sedimentada em instituições e decisões prévias, e desenvolvê-los como jurídicos. Isto por si só, no entanto, não anula a separação entre Direito e Moral, da mesma forma que o recurso às quatro operações aritméticas no Direito Financeiro não anula a separação entre Direito e matemática.

A teoria dos princípios, na roupagem que ela recebeu de Alexy, postula uma vinculação ainda mais forte entre Direito e moral, segundo a qual o Direito não pode estar em grande desconformidade com a moral correta sem que perca sua validade. Tal tese não decorre, entretanto, do argumento de princípio. ${ }^{32}$ Por último, mas não menos importante, o

29 DWORKIN, R. Law's Empire. Cambridge: Harvard University Press, 1986. p. 255-257. A crítica correspondente de SIECKMANN. Rechtssystem und praktische Vernunft. p.145-160-163, é motivada pela teoria da validade e não pela teoria dos princípios.

30 BVerfGE 27. I (6); BVerfG, NJW 2006, 751/757 e ss.

31 Para um argumento similar na discussão do positivismo americano, PRIEL, D. Oxford J. Legal Stud. 25: 2005. p. 675-696.

32 Nesse sentido, também sobre o argumento da correção de Dworkin, KOCH, H.-J. Zur Methodenlehre des Rechtspositivismus. (In) DREIER, R. (Hg.), Rechtspositivismus und Wertbezug des Rechts. ARSP Beiheft 37: 1988. p. 152-157, 160.

Cadernos do Programa de Pós-Graduação em Direito PPGDir./UFRgS | Edição Digital | Porto Alegre | Volume X | Número 3 | 2015 | P. 3 - 38 


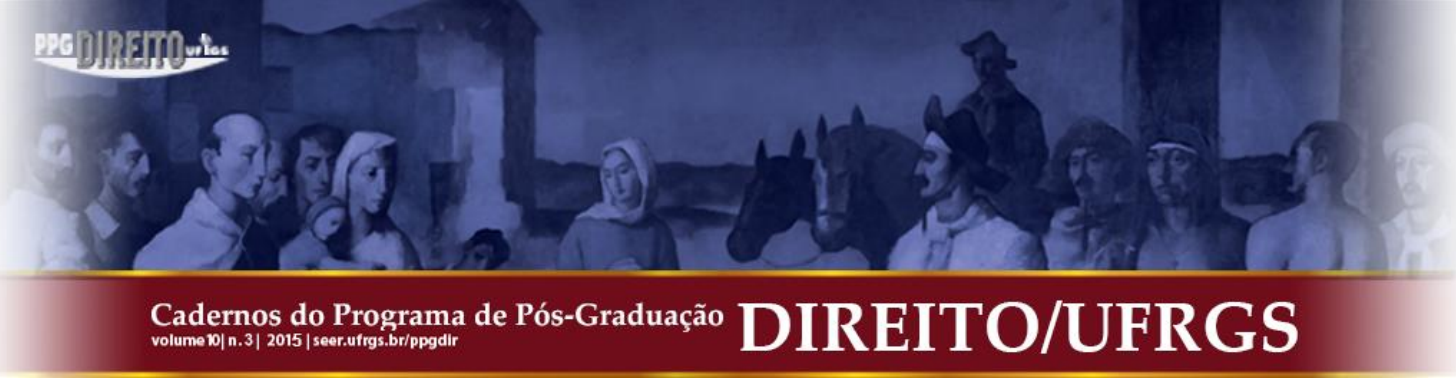

próprio Dworkin demostrou que, embora o Direito faça empréstimos da moral no âmbito da aplicação jurídica, disto não resultam, entretanto, quaisquer medidas sobre que tipo de moral será adotado como referência. ${ }^{33}$ Da mesma forma como o Direito recorre à forma da matemática, da cronometria etc. na aplicação jurídica, que constitui em uma sociedade o fundamento da vida em comum, relaciona-se ele com a moral. Neste sentido, a aplicação jurídica em um regime jurídico injusto (Unrechtsregime) também pode recorrer a uma moral injusta (Unmoral), a fim de se prover de valores e princípios (Wertungen, Grundätzen und Prinzipien) correspondentes para construção de estruturas dogmáticas, tipologias de casos, decisões singulares etc. Os postulados excedentários dos defensores da teoria dos princípios não estão atrelados a princípios, senão ao seu conceito de Direito $^{34}$ ou de validez ${ }^{35}$, que demandariam uma crítica própria.

Para a consideração do caso principal de aplicação da teoria dos princípios enquanto uma teoria dogmática dos direitos fundamentais é de se registrar que, não por acaso, a teoria dos princípios foi desenvolvida em ambos os lados do Atlântico, e de forma independentemente uma da outra, não como uma teoria dogmática, mas em reação a uma teoria insuficiente da aplicação do Direito. Do ponto de vista genético não sugere, de qualquer forma, formular uma teoria dos princípios como teoria dogmática, especialmente como uma teoria dogmática dos direitos fundamentais. Em sua gênese, a teoria dos princípios está situada em outro nível de abstração: ela pertence ao campo da teoria geral da aplicação jurídica, não ao nível da dogmática concreta. Assim como a subsunção, analogia ou o argumento a contrário não podem constituir uma dogmática setorial, algo como o

33 DWORKIN. Bürgerrechte ernstgenommen. p. 102-108.

34 ALEXY, R. Begriff und Geltung des Rechts. Freiburg: Alber, 1992. p. 64-69, 129-135, que liga o conceito de Direito não apenas com a pretensão de correção moral, mas com a própria correção moral; crítico à fundamentação de Alexy acerca da conexão, HILGENDORF, E. Argumentation in der Jurisprudenz. Berlin: Duncker \& Humblot, 1991. p. 115 e ss.

35 SIECKMANN. Regelmodelle und Prinzipienmodelle des Rechtssystems. 1990, p. 100-102, que, ao lado da efetividade de uma norma e sua validade ética e relativa no âmbito de um sistema jurídico, conhece uma "validez jurídica absoluta", cujo status teórico, entretanto, permanece turvo, no sentido de não estar claro sobre se se trata de uma validade jurídica de estilo próprio ou apenas de uma validade relativa com vistas à moral correta. As explicações permanecem obscuras: "Ambas as construções são problemáticas. A aceitação de um dever ser jurídico de estilo próprio conduz a problemas filosóficos difíceis, sobre se existe unidade de dever ser [...] Ademais, é uma definição [...] do conceito de validade jurídica em que ela mesma emprega o conceito de "jurídico", o que a expõe à objeção de circularidade. A segunda alternativa, de se falar em um mandamento de aplicação moral, conduz facilmente a mal-entendidos e ao debate em torno do juspositivismo e do jusnaturalismo. Para a finalidade destes estudos não precisa ser decidido, se se está a falar de um mandamento apenas jurídico ou também moral." Op. cit., p. 246; ver também, do mesmo autor, Modelle des Eigentumsschutzes. p. 145-148.

Cadernos do Programa de Pós-Graduação em Direito PPGDir./UFRGS | Edição Digital | Porto Alegre | Volume X | Número 3 | 2015 | P. 3 - 38 


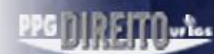

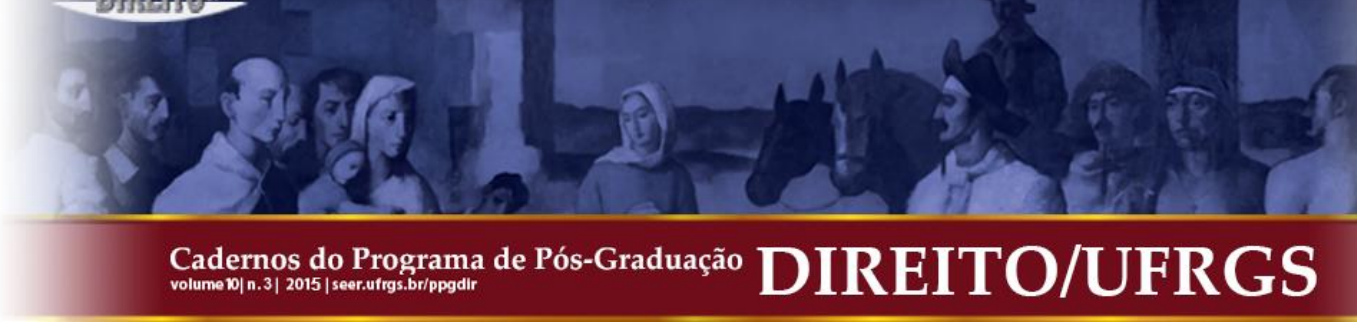

enriquecimento sem causa, também um princípio não pode sê-lo. Eles podem ser utilizados para formação de uma dogmática, mas em si não constituem uma dogmática.

\section{O ERRO DE TEORIA DO DIREITO: A DISTINÇÃO ESTRUTURAL ENTRE PRINCÍPIOS E REGRAS}

A tese lógico-jurídica da teoria dos princípios parte do pressuposto de que regras e princípios se diferenciam em sua estrutura formal. Enquanto as regras ordenariam uma consequência jurídica definitiva, preveriam os princípios suas consequências jurídicas apenas prima facie. ${ }^{36}$ Esta estrutura diferente de ambos os tipos de normas se manifestaria principalmente no seu comportamento de colisão. Enquanto no caso de colisão entre regras deveriam ser introduzidas exceções em uma delas ou uma de ambas deveria ser declarada nula, a validade dos princípios em caso de colisão permaneceria não afetada, uma vez que eles reivindicariam apenas um efeito prima facie e, em caso de colisão, somente restariam concretizados em uma regra definitiva por meio da ponderação no caso individual. ${ }^{37}$ Regras e princípios constituem, por isso, tipos de normas categoricamente distintos.

Uma análise do trato da ordem jurídica com colisões de normas mostra, porém, que regras e princípios são estruturados de forma idêntica e que se diferenciam não em sua estrutura, mas apenas no conteúdo contingente de uma estrutura unitária. ${ }^{38}$ Isto fica claro quando se leva em conta como e, quão diferente, as colisões entre normas são resolvidas. A ordem jurídica reage a colisões entre normas com regras de colisão, que possuem conteúdos substancialmente diferentes e podem, dependendo da apresentação, ser pensadas como regras independentes ou ser integradas na regra como supostos de fato excepcionais

36 ALEXY, R. Theorie der Grundrechte. p. 88-90; SIECKMANN. Regelmodelle und Prinzipienmodelle des Rechtssystems. p. 67-71

37 ALEXY, R. Theorie der Grundrechte. p. 77-87; SIECKMANN. Regelmodelle und Prinzipienmodelle des Rechtssystems. p. 68.

38 Fora do círculo dos citados defensores da teoria dos princípios esta visão predomina. Exemplarmente: LERCHE, P. Übermaß und Verfassungsrecht, 2. ed. Goldbach: Keip, 1999. p. XXII: "Em minha opinião, a diferença entre estas categorias é apenas de natureza quantitativa." MARMOUR, A. The Separation Thesis and the Limits of Interpretation. Can. J.L.\& Juris. 12. 1999. p. 135-145 e ss.; SCHILCHER, B. Prinzipien und Regeln als Elemente einer Theorie des gebundenen Ermessens, (In) SCHILCHER, B.; KOLLER, P.; FUNK, B.-C. Regeln, Prinzipien und Elemente im System des Rechts. Wien: Österreich, 2000. p. 153-164, 169; REIMER, F. Verfassungsprinzipien. Berlin: Duncker \& Humblot, 2001. p. 179-182; na literatura anglosaxônica, já HART. Concept of Law. p. 259 e ss.; para uma possível reconstrução lógico-jurídica da diferença gradual, VERHEIJ, B.; HAGE, J.; VAN DEN HERIK, H. J. An integrated view on rules and principles. Artificial Intelligence and Law 6: 1998. p. 3-26.

Cadernos do Programa de Pós-Graduação em Direito PPGDir./UFRGS | Edição Digital | Porto Alegre | Volume X | Número 3 | 2015 | P. 3 - 38 


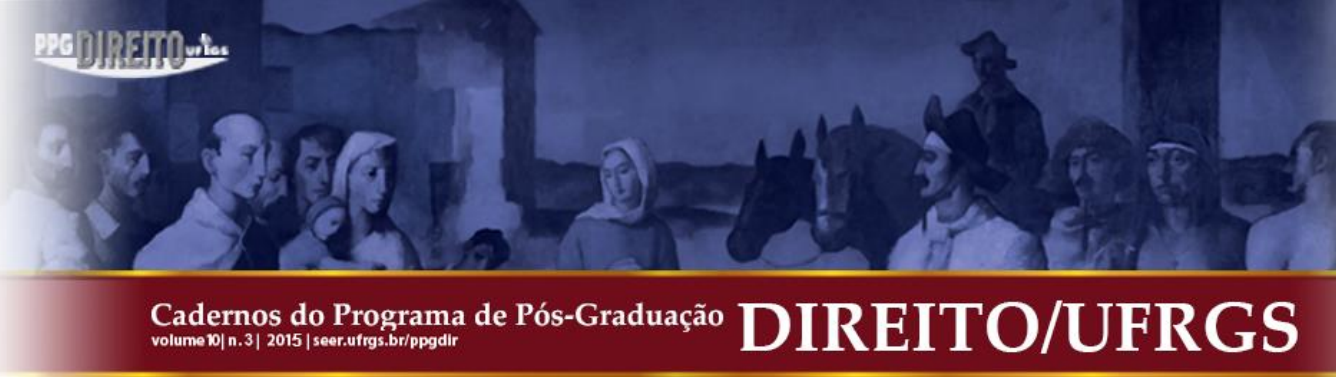

(Ausnahmetatbestände). ${ }^{39}$ Essas regras de colisão conduzem a que, ou uma das normas colidentes perde sua vigência, ou serão incorporados supostos de fato excepcionais a uma ou a ambas as normas, que evitem a colisão. ${ }^{40} \mathrm{O}$ mandamento da ponderação otimizadora é com isso apenas um conteúdo possível de tal suposto de fato excepcional. A ponderação otimizadora se diferencia de outros supostos de fato excepcionais da mesma forma que eles se diferenciam entre si quanto ao conteúdo. O conteúdo distinto dos outros supostos de fato excepcionais não afeta, entretanto, a estrutura das normas. Assim como o princípio da Lexposterior não cria um tipo de norma estruturalmente próprio, o princípio da ponderação também não o faz.

Isto pode ser demonstrado com duas normas que Alexy cita como exemplos de princípios. ${ }^{41}$ A norma N1 autoriza o Estado a adotar medidas para proteger seus interesses externos. A N2 concede aos cidadãos liberdade de imprensa.

N1: Se uma ação ameaça os interesses externos do Estado, então ela deve ser proibida.

N2: Se uma ação é útil à imprensa, então o Estado deve se abster de proibi-la.

Para ambas as normas há intersecções de supostos de fatos nas quais tanto uma como outra são aplicáveis. Para estas intersecções de supostos de fatos a ordem jurídica deve introduzir uma regra de colisão, que possa ser incorporada como exceção no suposto de fato das normas. Esta regra de colisão pode ser algo como o princípio da Lex-posterior $(\mathrm{Ca})$. Fosse a norma N1 sobre a proteção do Estado ainda provinda do período de uma ditadura militar e a norma N2 do período posterior à reviravolta democrática, então o princípio da Lex-posterior não estaria em si excluído para as normas N1 e N2. Tal situação apontaria para o fato de que, caso a N1 não fosse totalmente incompatível com a nova ordenação, a N1 seria completada interpretativamente com um suposto de fato excepcional.

N1a: Se uma ação ameaça os interesses externos do Estado $e$ tal ação não é útil para a imprensa, então ela deve ser proibida.

N2a: Se uma ação é útil para a imprensa, então o Estado deve se abster de proibi-la.

A interpretação de ambas as prescrições também poderia conduzir, no entanto, a regras de colisão que não operassem apenas em detrimento de uma das normas envolvidas. Para isto, a regra de colisão Ca deve ser ligeiramente modificada, num sentido democrático funcional: nem toda atividade da imprensa deve gozar de precedência com relação aos interesses

\footnotetext{
${ }^{39}$ DWORKIN. Bürgerrechte ernstgenommen. p. 62.

${ }^{40}$ ALEXY, R. Theorie der Grundrechte. p. 77.

${ }^{41}$ ALEXY, R. Theorie der Grundrechte. p. 147.
}

Cadernos do Programa de Pós-Graduação em Direito PPGDir./UFRGS | Edição Digital | Porto Alegre | Volume X | Número 3 | 2015 | P. 3 - 38 


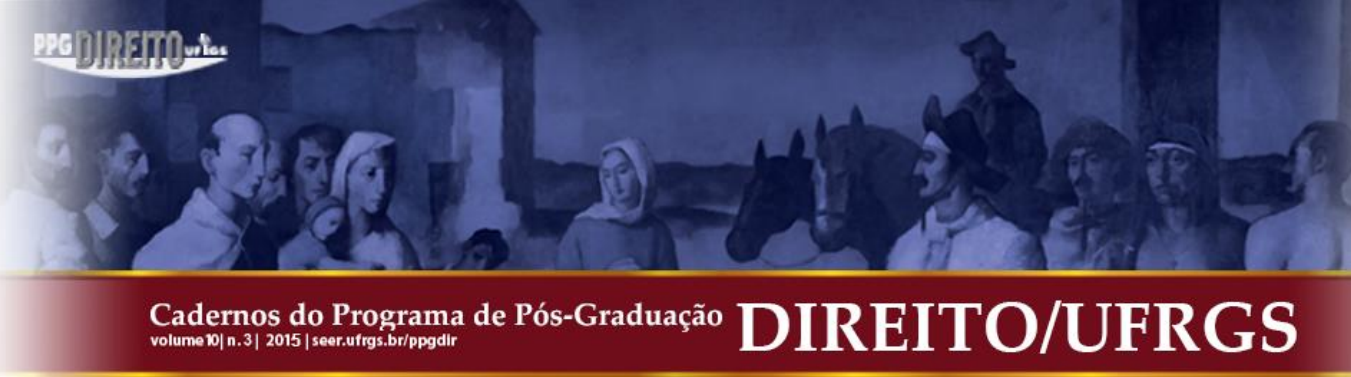

exteriores do Estado, mas tão somente aquela que objetive a formação da opinião política. No caso desta norma de colisão $\mathrm{Cb}$ deveriam ambas as normas, N1 e N2, ser ampliadas por meio de uma situação de fato excepcional.

N1b: Se uma ação ameaça os interesses externos do Estado e tal ação não é útil para formação da opinião política, então ela deve ser proibida.

N2b: Se uma ação é útil para a imprensa e não ameaça os interesses externos do Estado, ou objetiva a formação da opinião política, então o Estado deve se abster de proibi-la.

A regra de colisão pode apresentar elementos de peso, sem com isso produzir um princípio no sentido da teoria dos princípios. Isto poderia ser proporcionado por uma redução teleológica de N2, de forma que ela devesse valer apenas para elevados interesses exteriores. A partir desta regra de colisão Cc ter-se-ia:

N1d: Se uma ação ameaça elevados interesses exteriores do Estado, então ela deve ser proibida.

N2c: Se uma ação é útil para a imprensa e não ameaça elevados interesses exteriores do Estado, então o Estado deve se abster de proibi-la.

Também aqui a valoração da ameaça precisaria de um sopesamento, mas diferentemente da lei da ponderação, tal valoração não seria pensada a partir do prejuízo para a liberdade de imprensa. Seria necessário apenas estabelecer se o interesse exterior ameaçado seria elevado.

A partir da regra de colisão Cc é apenas um pequeno passo para uma regra de colisão e um correspondente suposto de fato de fato excepcional, que é próprio das normas que a teoria dos princípios concebe como princípios. Se uma regra de colisão $\mathrm{Cd}$ se assenta sobre interesses exteriores "preponderantes" ao invés de "elevados", nascem duas normas que exigem a ponderação entre a ameaça aos interesses exteriores e o prejuízo da liberdade de imprensa. Então elas podem ser compreendidas como mandamentos de otimização no sentido de Alexy, os quais poderão ser equacionados a partir da lei da ponderação ${ }^{42}$.

N1d: Se uma ação ameaça interesses exteriores do Estado preponderantes, então ela deve ser proibida.

N2d: Se uma ação é útil para a imprensa e não ameaça interesses exteriores do Estado preponderantes, então o Estado deve ser abster de proibi-la.

${ }^{42}$ ALEXY, R. Theorie der Grundrechte. p. 145-154.

Cadernos do Programa de Pós-Graduação em Direito PPGDir./UFRGS | Edição Digital | Porto Alegre | Volume X | Número 3 | 2015 | P. 3 - 38 


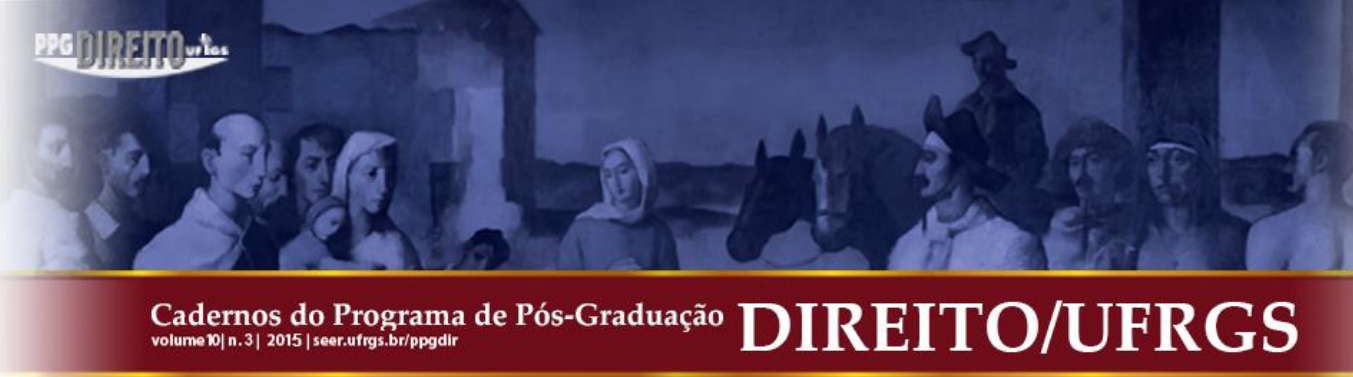

O deslocamento semântico de "elevado" para "preponderante" deixa a estrutura da norma intocada. Não existe diferença estrutural entre as normas $\mathrm{Nc}$ e $\mathrm{Nd}$, e sim uma diferença contingente de conteúdo. Tanto uma como outra são normas de um tipo condicional com uma cláusula de exceção, que encontramos na ordem jurídica de forma onipresente e com os conteúdos mais variados.

Sopesamentos relativos também são encontrados em outras formas que não os mandamentos de otimização ontologicamente concebidos pela teoria dos princípios. Neste sentido há na dogmática dos direitos fundamentais uma proposta de interpretação do princípio da proporcionalidade que, ao lado da necessidade de uma medida, exige apenas um simples controle amplo de coerência, no sentido de que a medida não esteja em demasiada desproporcionalidade em relação ao fim perseguido pelo legislador, ou seja, que não sejam usados canhões para a tirar em pardais. ${ }^{43}$

N1e: Se uma ação ameaça os interesses exteriores do Estado e a ameaça não está em grande desacordo com sua proibição, então ela deve ser proibida.

N2e: Se uma ação é útil para a imprensa e não ameaça os interesses exteriores do Estado ou se uma proibição estivesse em grande desacordo com a medida do perigo, então o Estado deve se abster de proibi-la.

Não há limites para a fantasia desenvolver supostos de fato excepcionais. Entretanto, normas com supostos de fato excepcionais diversos em termos de conteúdo não se diferenciam em sua estrutura normativa, nem mesmo aquelas que contêm um mandamento de otimização. $^{44}$ Assim como não parece sensato assumir a regra da relevância ou da desproporcionalidade como um tipo normativo ontologicamente próprio para ao princípio da Lex-posterior, também não o é evidente para o princípio da proporcionalidade entendido como mandamento de otimização.

O conteúdo das regras de colisão não é apenas contingente, mas também pode ser controverso. A decisão acerca da interpretação correta do princípio da proporcionalidade em

43 PIEROTH, B.; SCHLINK, B. Grundrechte. 21. ed. Heidelberg: C.F. Müller, 2005. nota lateral 294; POSCHER, R. Grundrechte als Abwehrrechte. Tübingen: Mohr Siebeck, 2003. p. 224; fundamentalmente, no sentido de uma posição mínima, SCHLINK, B. Abwägung im Verfassungsrecht. Berlin: Duncker \& Humblot, 1976. p. 76-78, 192-195; para princípios constitucionais (Verfassungsgrundsätze) em geral HAIN, K-E. Die Grundsätze des Grundgesetzes. Baden-Baden: Nomos, 1999. p. 158; Cf. também REIMER, F. Verfassungsprinzipien. p. 326-348: Niveau- und Rahmenbestimmungen.

${ }^{44}$ Cf. a reconstrução baseada em regras de uma colisão de princípios já em ALEXY, R. Zum Begriff des Rechtsprinzips. (In) ALEXY, R. Rechts, Vernunft, Diskurs. Frankfurt: Suhrkamp, 1995. p. 177-196; ver também SIECKMANN. Regelmodelle und Prinzipienmodelle des Rechtssystems. p. 65; BOROWSKI, M. Grundrechte als Prinzipien. p. 76 e ss.

Cadernos do Programa de Pós-Graduação em Direito PPGDir./UFRgS | Edição Digital | Porto Alegre | Volume X | Número 3 | 2015 | P. 3 - 38 


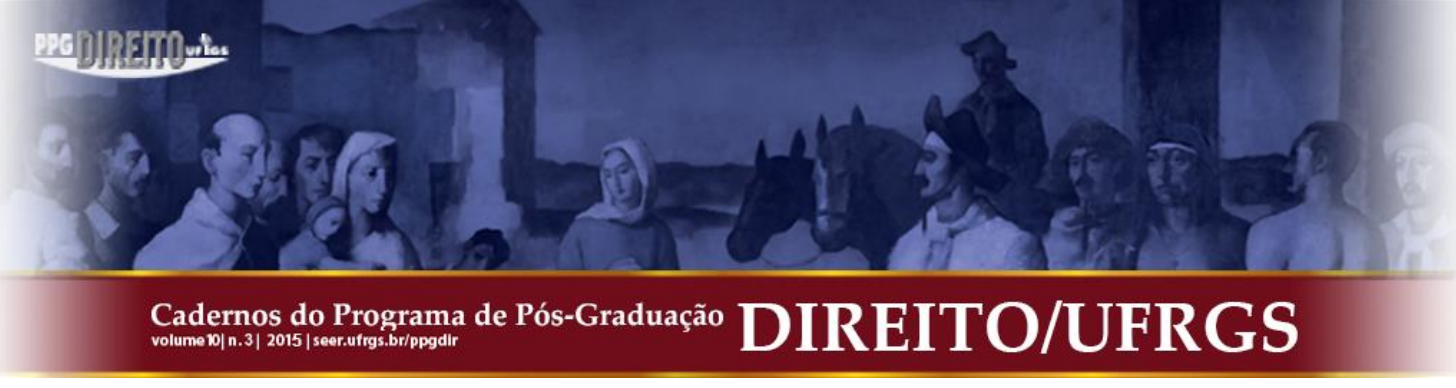

sentido estrito como proibição de desproporcionalidade, como acima descrito, ou como mandamento de otimização não decorre de diferenças pseudo-ontológicas de tipos de normas distintos, mas deve ser tomada com argumentos jurídico-constitucionais. Em parte, o próprio legislador constitucional também positivou regras de colisão que se mostram incomparavelmente mais complexas que as acima listadas. Neste sentido, quando se pensar em colisão de direitos fundamentais, ${ }^{45}$ podem as reservas de lei ser compreendidas como tais regras de colisão. ${ }^{46}$ A regulação do caso de colisão ocorre de forma reflexiva: o legislador constitucional não o regulou diretamente, mas deixou a regulamentação fundamentalmente a cargo do legislador ordinário. ${ }^{47}$

Que os mandamentos de otimização não são categorias de norma de estilo próprio que se contrapõem a regras, nem os defensores da teoria dos princípios contestam mais. ${ }^{48}$ Segundo Alexy, entretanto, isso não faz ruir a teoria dos princípios, mas “apenas joga sobre ela uma luz mais nítida". ${ }^{49}$ Seria o caso agora de

[...] diferenciar entre mandamentos que devem ser otimizados (zu optimierende Gebote) e os mandamentos para otimizar (Gebote zu optimieren). Os mandamentos que devem ser otimizados são os objetos da ponderação. É possível designá-los como "dever ser ideais" ou como "ideais". 50

Para salvar a diferença ontológica entre princípios e regras deve agora ser feita uma diferenciação entre mandamentos de otimização e mandamentos que devem ser otimizados. Em termos lógico-jurídicos a idealidade do dever ser dos mandamentos que devem ser otimizados deveria corresponder a uma reiteração infinita de um mandamento de validade. ${ }^{51}$

Ao pensar um "dever ser ideal" e um "mandamento de validade infinitamente reiterado" sempre enquanto tal, esta tentativa de resgate, já difícil de realizar, se equivoca,

\footnotetext{
${ }^{45}$ Para um modelo de direitos fundamentais livre de colisões POSCHER, R. Grundrechte als Abwehrrechte. p. 198-203.

${ }^{46}$ BOROWSKI, M. Grundrechte als Prinzipien. p. 107 e ss.

${ }^{47}$ Acerca da reflexividade dos direitos fundamentais, POSCHER, R. Grundrechte als Abwehrrechte.

${ }^{48}$ SIECKMANN. Regelmodelle und Prinzipienmodelle des Rechtssystems. p. 65 e ss; ALEXY, R. Zur Struktur von Rechtsprinzipien. (In) SCHILCHER, B.; KOLLER, P.; FUNK, B.-C. Regeln, Prinzipien und Elemente im System des Rechts. Wien: Österreich, 2000. p. 31-38 e ss.; da mesma forma AARNIO, A. Taking Rules Seriously, in: MAIHOFER, W.; SPRENGER, G. (Org.), Law and the States in modern Times. ARSP Beiheft 42. 1990. p. 187-192.

${ }^{49}$ ALEXY, R. Theorie der Grundrechte. p. 31-38 e ss. - grifo no original.

${ }^{50}$ ALEXY, R. Theorie der Grundrechte. p. 31-38 e ss.

51 SIECKMANN, Zur Analyse von Normkonflikten und Normabwägungen. (In) MEGGLE, G. Analyomen, 2. Proceedings of the 2nd Conference "Perspectives in Analytical Philosophy", Bd. III. Berlin: de Gruyter, 1994.p. 349-352; fundamentalmente de acordo com esta reconstrução, ALEXY, R. Theorie der Grundrechte. p. 31-39 e ss.
} 


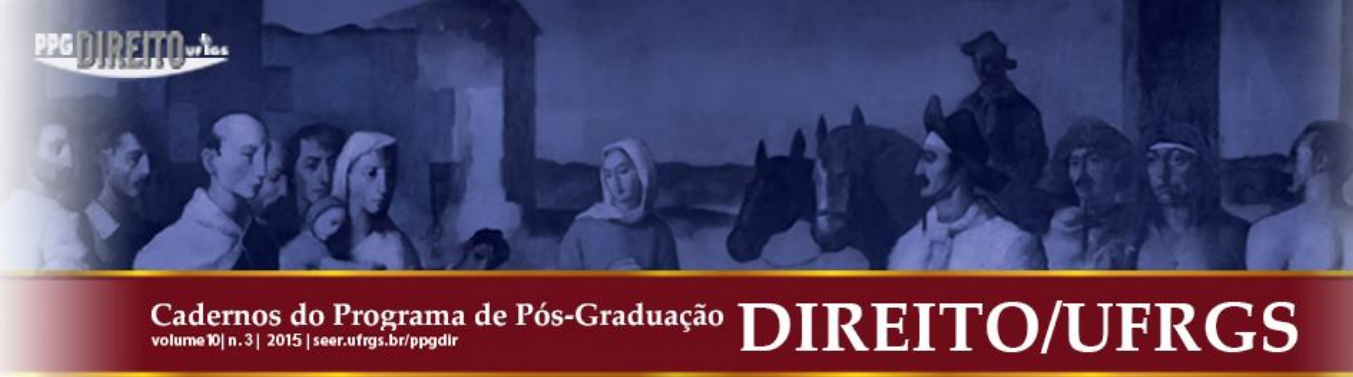

pois para reconstrução de mandamentos de otimização não são necessários mandamentos que devam ser otimizados, mas apenas objetos que devam ser otimizados. Mandamentos de otimização ordenam que algo seja otimizado, mas não ordenam que mandamentos sejam otimizados. Na compreensão da teoria dos princípios, o art. 2, inciso 2 da Lei Fundamental contém algo como um mandamento para otimização da saúde e da integridade corporal ou também da vida humana. No entanto, saúde e vida não são mandamentos. Não são objetos normativos, mas sim empíricos. Uma norma que previsse a otimização da pressão dos pneus para veículos motorizados também seria um mandamento de otimização. Também não é o caso, que os objetos dos mandamentos de otimização tenham que ter um caráter normativo para esclarecer a normatividade destes. ${ }^{52}$ Os objetos dos mandamentos de otimização adquirem normatividade por meio da ordem para intensificar um objeto, de acordo com as possibilidades fáticas e jurídicas, contida no mandamento de otimização. Conforme demonstra o exemplo da pressão dos pneus, os objetos dos mandamentos de otimização em si não precisam de modo algum ser identificados como normativos. A normatividade dos mandamentos de otimização resulta apenas dos mandamentos para otimizar. Não é necessário para tal, como objeto da otimização, um mandamento que deve ser otimizado. É possível otimizar tudo, como, por exemplo, doença e morte, comprimento, largura, altura, temperatura, tempo etc. Da mesma forma, a direção da otimização não é estipulada pelo objeto do mandamento, mas sim pelo mandamento da otimização, que estabelece principalmente por meio do contexto do objeto, se o objeto deve ser maximizado ou minimizado relativamente às possibilidades fáticas ou jurídicas. Assim se compreende diante de um direito fundamental que em princípio proíbe a interferência na saúde - se ele for compreendido como mandamento de otimização - que ela deva ser otimizada e não minimizada, de acordo com as possibilidades fáticas e normativas. Diferente poderia seria ser o comportamento diante da interpretação teórico-principiológica de um regulamento para pesticidas. Entretanto, nem o mandamento da otimização nem a direção normativa do mandamento resultam do "objeto da ponderação", senão do "mandamento para otimizar".

Que mandamentos de otimização são de fato mandamentos, que, sem embargo, normalmente não são relacionados a um mandamento, fica claro em comparação com casos nos quais isto excepcionalmente não ocorre. Mandamentos de otimização podem se relacionar com quaisquer objetos. Podem inclusive, mas não devem necessariamente, se referir a objetos

\footnotetext{
52 Assim, entretanto, SIECKMANN. Regelmodelle und Prinzipienmodelle des Rechtssystems. p. 66.

Cadernos do Programa de Pós-Graduação em Direito PPGDir./UFRGS | Edição Digital | Porto Alegre | Volume X | Número 3 | 2015 | P. 3 - 38
} 


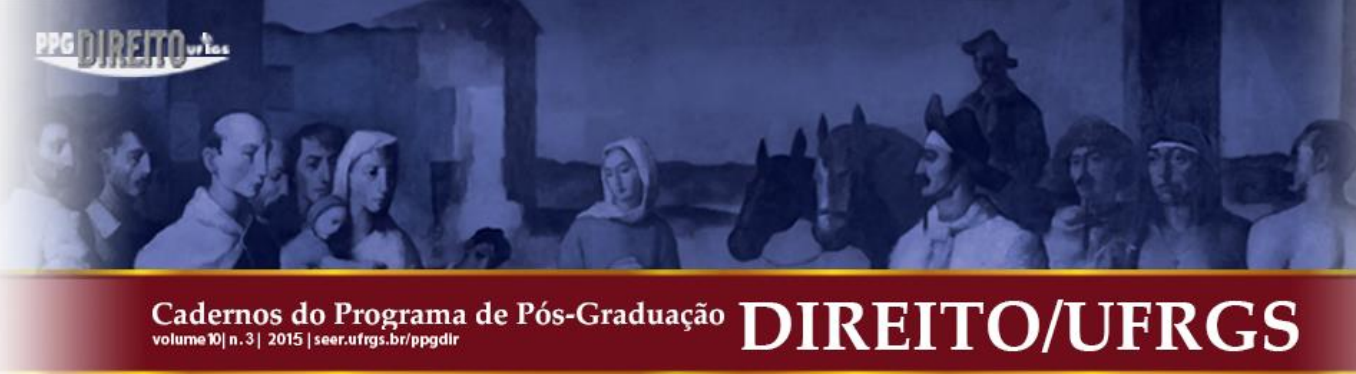

normativos. Normas também podem ser otimizadas e, com isso, também mandamentos. Assim, regramentos de Direito penal que ainda contam com lacunas de punibilidade (Strafbarkeitslücken), podem ser otimizados a partir da publicação de leis que preencham estas lacunas. Entretanto, por um lado, mesmo que os direitos fundamentais sejam compreendidos como mandamentos de otimização, eles normalmente não têm como objeto regramentos correspondentes, ${ }^{53}$ mas sim situações empíricas ou liberdades; por outro lado, os regramentos, com os quais os mandamentos de otimização também podem teoreticamente se relacionar, não se encontram na esfera misteriosa de um “dever ser ideal” e também não são associados a mandamentos de validade reiterados infinitamente. São, isso sim, simples mandamentos reais.

Os mandamentos de otimização não precisam, em virtude de sua estrutura normativa, se relacionar a mandamentos - muito menos a um "dever ser ideal" ou a mandamentos de validade reiterados infinitamente -, nem tampouco os direitos fundamentais, que são tomados como paradigmas pelos defensores da teoria dos princípios, se relacionam, em regra, com objetos normativos. Mesmo com a tentativa adicional de provar a existência de seu objeto, a teoria dos princípios não é capaz de convencer. Acerca dos mandamentos de otimização, que são objeto da teoria dos princípios, poderia não apenas ser demonstrado que se tratam de regras, mas também que os próprios defensores da teoria dos princípios não afirmam mais outra coisa sobre eles. Na medida em que a teoria dos princípios procura nos mandamentos de otimização princípios como objetos ideais, sua análise teórico-normativa dos mandamentos de otimização se equivoca. Medida pelos seus próprios parâmetros ontologizantes, a teoria dos princípios é uma teoria sem objeto.

\section{A REINCIDÊNCIA NO ERRO METODOLÓGICO: O CONCEITO DE REGRA DA TEORIA DOS PRINCÍPIOS}

A teoria dos princípios tem uma preocupação metodológica. Regras e princípios são por ela diferenciados também metodologicamente. Enquanto a concepção de subsunção é vinculada é ao conceito de regra, a ponderação é conectada metodicamente com o conceito de princípio.

${ }^{53}$ Direitos fundamentais caracterizados normativamente apresentam peculiaridades.

Cadernos do Programa de Pós-Graduação em Direito PPGDir./UFRGS | Edição Digital | Porto Alegre | Volume X | Número 3 | 2015 | P. 3 - 38 
A aplicação de regras ocorre por meio da subsunção de um estado de coisas/situações de fato (Sachverhalt) ao seu suposto de fato (Tatbestand) e da dedução de uma consequência [...] A aplicação de princípios exige, em contraposição [...], a ponderação entre os princípios em colisão. ${ }^{54}$

Para teoria dos princípios existem metodicamente dois processos de aplicação do Direito: a subsunção, conduzida hermeneuticamente, diante de uma regra inequívoca, ou, a ponderação de princípios, que dirige todos os casos que não correspondem ao ideal da subsunção. A partir deste ponto de partida metodológico, os princípios poderiam ser respectivamente reconhecidos na ordem jurídica na medida em que a subsunção do estado de coisas a uma norma encontrasse dificuldades. E ninguém negaria que a subsunção a dispositivos de direitos fundamentais como "a arte é livre" é difícil. Por conseguinte, os direitos fundamentais devem ser princípios, quod erat demonstrandum (q. e. d.).

O caráter questionável desta dedução, do ponto de vista metodológico-jurídico, reside menos no conceito de princípio do que no conceito de regra adotado pela teoria dos princípios. Seu conceito de regra está baseado em um ideal jurídico-conceitual ${ }^{55}$ que, de um lado, deveria ser superado com a teoria dos princípios, mas que, de outro, permanece a ela subjacente em seu conceito de regra. Isto também fica claro nos exemplos que são dados para o conceito de regra. As regras que aparecem na teoria dos princípios - como a ordem de deixar a sala ao soar a campainha ${ }^{56}$; o horário de abertura da loja entre 7 e 19 horas ${ }^{57}$; o pagamento de um tributo com caráter impessoal (Kopfsteuer) no valor de 1.000 marcos $^{58}$ são regularmente tão concretas, que o ideal tradicional da subsunção parece lhes corresponder. Da mesma forma, as regras que devem resultar da colisão de princípios são, ao seu turno, tão concretas, que sua aplicação surge sempre aparentemente como possível sem maiores argumentações ou valorações.

Não obstante, a aplicação de uma norma jurídica à riqueza de situações de fato ou estados de coisas que lhe são trazidos para consideração não se limita fundamentalmente, em qualquer norma, à alternativa entre subsunção, por meio de um simples seguir a regra em

\footnotetext{
54 SIECKMANN. Regelmodelle und Prinzipienmodelle des Rechtssystems. p. 18; ver também ALEXY. On Balancing and Subsumption. p. 433.

55 Crítico ao conceito de regra da teoria dos princípios de Dworkin já KOCH. Zur Methodenlehre des Rechtspositivismus, p. 152 e ss.; Hart também o rejeita como interpretação equivocada de seu conceito de regra. HART. Concept of Law. p. 263.

${ }^{56}$ ALEXY, R. Theorie der Grundrechte. p. 78.

${ }^{57}$ ALEXY, R. Theorie der Grundrechte. p. 77.

${ }^{58}$ SIECKMANN. Regelmodelle und Prinzipienmodelle des Rechtssystems. p. 70. 


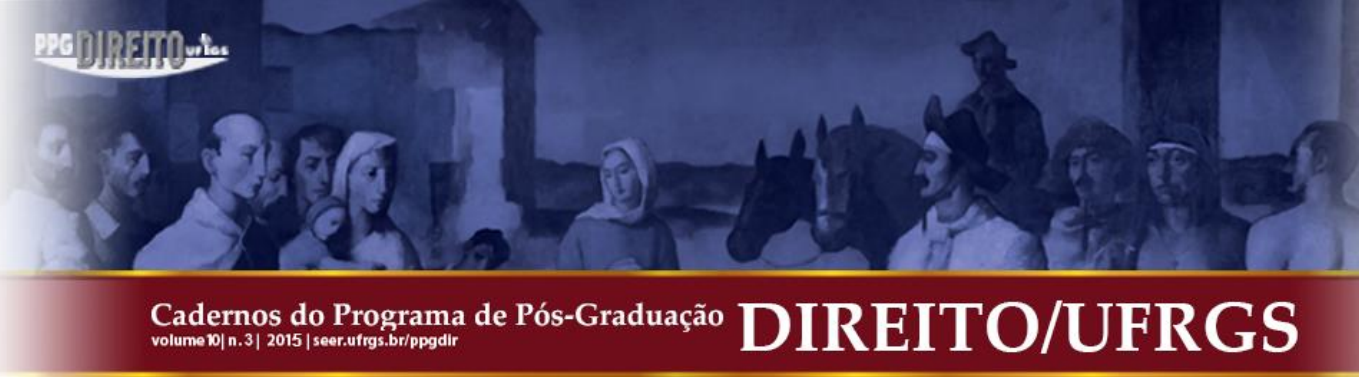

casos fáceis ${ }^{59}$, e ponderação, no sentido de um mandamento de otimização, em todos os outros casos restantes. A aplicação de uma norma à riqueza de situações de fato que lhe são trazidos para consideração reúne, pelo contrário, um pacote complexo de técnicas de aplicação jurídica, dentre as quais estão sempre a subsunção, por meio de um simples seguir a regra e, certamente também, às vezes, a ponderação, no sentido de um mandamento de otimização, mas também ainda uma gama de outros procedimentos e as diferentes combinações de todas estas técnicas. A aplicação jurídica pode, em qualquer norma, consistir num simples seguir a regra em casos fáceis, mas também, consistir em reflexões analíticas mais complexas no caso de normas ou estados de coisas mais complexos, e ainda em argumentações ou valorações mais complexas em casos difíceis, nos quais a ponderação de bens, no sentido de um mandamento de otimização, desempenha um papel. De que forma a aplicação jurídica acontece, não é uma questão relativa à norma que está sendo aplicada, mas sim da situação que deve ser julgada de acordo com a norma. Basicamente existem para cada norma, mais ou menos frequentemente ou raramente, casos fáceis, nos quais a aplicação pressupõe apenas um seguir a regra e, outros casos, nos quais são necessárias reflexões, argumentações e valorações mais amplas e, sob certas circunstancias, também ponderações. Isto também pode ser demonstrado em relação às normas que a teoria dos princípios tem à disposição como como modelos exemplares para o conceito de regra. Deve a sala ser também abandonada ao soar a campainha se com isso estivesse necessariamente relacionado um perigo para a saúde dos alunos da escola em virtude de temperaturas excepcionais, alerta de poluição atmosférica (Smog-Alarm) etc.? Qual o peso teria a vontade do legislador para lidar formalmente com determinações sobre alarmes de incêndio etc.? Para além dos casos fáceis, a aplicação pressupõe uma abundância de reflexões, nas quais a ponderação de argumentos desempenha um papel, que, por vezes, será executado no sentido de uma otimização.

Da perspectiva de uma teoria da aplicação do Direito, a teoria dos princípios se mostra como a tentativa de escolher dois processos, entre a ampla gama daqueles utilizados na aplicação jurídica, quais sejam, a aplicação por meio de um simples seguir a regra em casos fáceis e a ponderação de bens otimizadora, e hipostaziá-los como diferentes normas e, com isso, chegar não à diferença entre dois tipos de técnica de aplicação distintos, mas a dois a dois tipos de normas distintos. Contra isto depõe o fato de que, em primeiro lugar, ambas as

59 Sobre isso, em breve, ROSCHER, R. Einfache Fälle; acerca da diferenca entre seguir uma regra e interpretação, WITTGENSTEIN, L. Philosophische Untersuchungen. ANSCOMBE, G.E.M.; WRIGHT, G.H.; REES, Rush (Org.), (1953), (In) Werkausgabe, Vol. 1, 2. ed. 1992, § 201.

Cadernos do Programa de Pós-Graduação em Direito PPGDir./UFRGS | Edição Digital | Porto Alegre | Volume X | Número 3 | 2015 | P. 3 - 38 


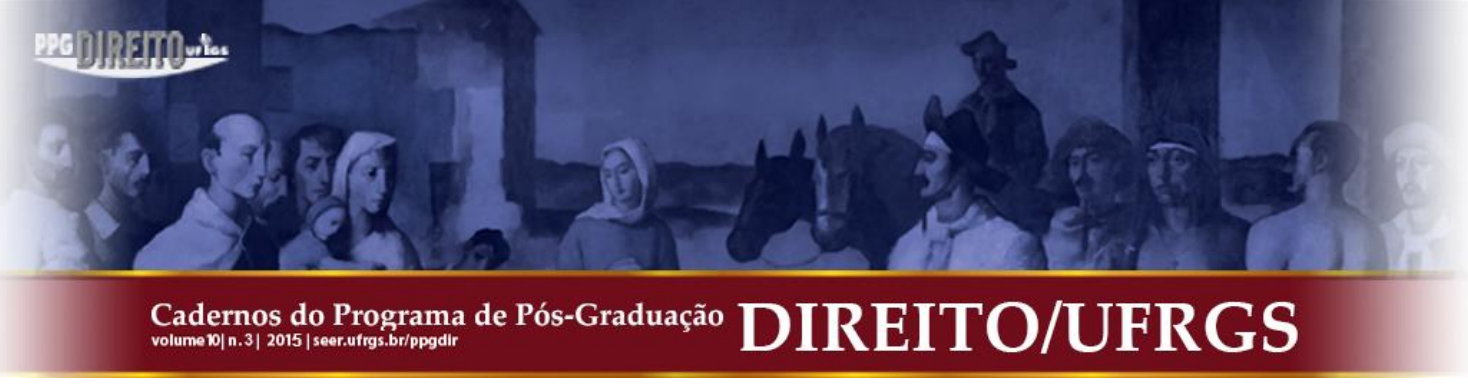

técnicas previstas pela teoria dos princípios encontram aplicação normalmente em qualquer norma; por isso, toda a norma é, no sentido da teoria dos princípios, tanto regra como princípio. Isto, em compensação, não autoriza que as normas sejam classificadas a partir do esquema princípio-regra em diferentes categorias. ${ }^{60} \mathrm{Em}$ segundo lugar, as técnicas de aplicação jurídica não se esgotam no dualismo entre um simples seguir regras e a ponderação de bens otimizadora. O processo de aplicação jurídica pode, isto sim, pressupor ainda uma grande gama de outros processos intelectuais, como para normas ou situações de fato mais complexas que exigem, ao lado do mero seguir regras, técnicas analíticas, mas não ponderação de bens. Segundo o esquematismo da teoria dos princípios, para cada uma destas técnicas analíticas deveria ser exigido um tipo próprio de norma. Da mesma forma, o procedimento junto a colisões entre bens jurídicos não se limita a processos de ponderação otimizadora. São também pensáveis reflexões sobre desproporcionalidade mais graves ${ }^{61}$ ou conceitos de posições mínimas ${ }^{62}$, da mesma forma como elas são defendidas com relação ao princípio da proporcionalidade. Para todo procedimento de aplicação do Direito que divergisse de um mero seguir a regra ou da otimização de bens, seriam exigidos tipos de normas específicos e, então, todos os tipos de normas deveriam ser novamente atribuídos a cada norma. Da perspectiva de uma teoria da aplicação jurídica, constitui um erro de categoria da teoria dos princípios ontologizar diferentes técnicas de aplicação de uma norma e considera-las como diferentes tipos de normas. ${ }^{63}$

Para uma teoria principialista dos direitos fundamentais isso significa, por outro lado, que da reduzida capacidade de subsunção direta dos direitos fundamentais não se pode

60 Isto explica o motivo pelo qual os defensores da teoria dos princípios são incapazes de classificar claramente normas individuais em uma ou outra categoria, mas apenas falam do "caráter duplo das normas de direitos fundamentais" ALEXY, R. Theorie der Grundrechte. p. 122-124 ou referem que "no âmbito das regras jurídicas existiriam elementos de princípios" KOCH, H. Die normtheoretische Basis der Abwägung (In) ERBGUTH, W. et.ali, Abwägung im Recht. Köln: Heymanns, 1996. p. 9-18, ou apontam para um "complexo entrelaçamento entre regras e princípios" MICHAEL, L. Methodenfragen der Abwägungslehre, (In) JöR 48. 2000. p. 169-176; no mesmo sentido, também no pensamento original acerca da separação DWORKIN. Bürgerrechte ernstgenommen. p. 64 e ss.

${ }^{61}$ PIEROTH, B.; SCHLINK, B. Grundrechte. nota lateral 294; POSCHER, R. Grundrechte als Abwehrrechte. p. 224.

${ }^{62}$ SCHLINK, B. Abwägung im Recht. p. 76-78, 192-195; comparar também HAIN, K-E. Die Grundsätze des Grundgesetzes. p. 158, que exige para os princípios constitucionais em geral em razão de fundamentos jurídicofuncionais apenas uma observação mínima e não otimização; ver também REIMER, F. Verfassungsprinzipien. p. 326-348: Niveau- und Rahmenbestimmungen.

63 Assim também GÜNTHER. Der Sinn für Angemessenheit. Frankfurt: Suhrkamp, 1988. p. 270-276; o argumento metódico também vale para a diferença entre princípios e regras com conteúdo estipulado completo ou incompleto (Festsetzungsgehalt) desenvolvida por HAIN, K-E. Die Grundsätze des Grundgesetzes. p. 99-106.

Cadernos do Programa de Pós-Graduação em Direito PPGDir./UFRgS | Edição Digital | Porto Alegre | Volume X | Número 3 | 2015 | P. 3 - 38 


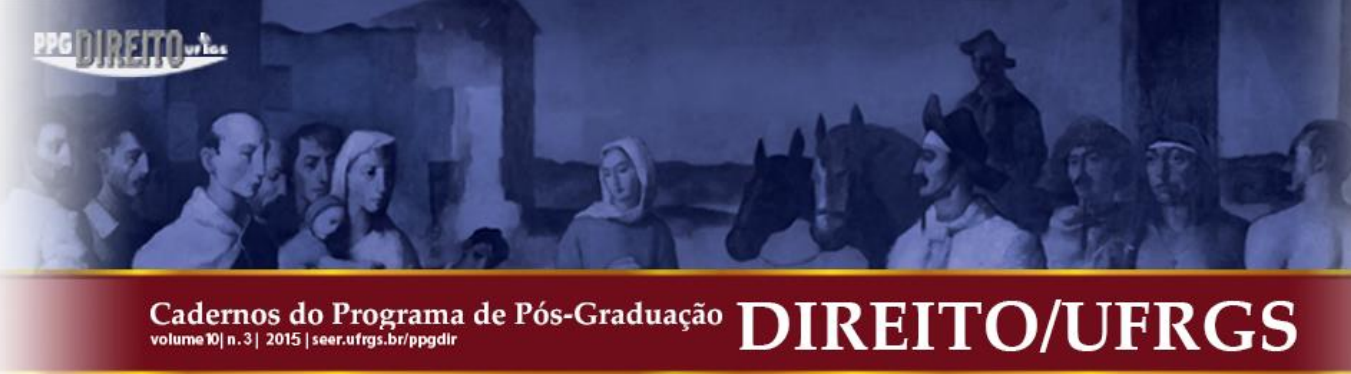

deduzir um caráter lógico-jurídico de princípio e, com isso, também não pode ser deduzido que eles devam ser compreendidos como simples mandamentos de otimização, que seriam mediados somente por meio da ponderação. Ao contrário, todo o instrumentário de técnicas jurídicas de aplicação e de argumentação também está à disposição para a dogmática dos direitos fundamentais. E este instrumentário também deve ser utilizado para sustentar uma determinada compreensão dos direitos fundamentais. A este respeito, nada resulta da equivocada divisão categorial do cosmos das normas em princípios e regras.

\section{A POSIÇÃo SISTEMÁTICA: A TEORIA dA ARGUMENTAÇÃo}

Em sua forma teórico-argumentativa a teoria dos princípios destaca não que princípios são normas com determinada estrutura ou métodos de aplicação, mas sim que são normas que possuem uma determinada função no âmbito da argumentação. Nesta linha, também apontava essencialmente Esser, que não via como função essencial dos princípios que eles fossem utilizados para que deles fosse retirada uma consequência jurídica direta para o caso concreto, mas sim para que eles fossem utilizados para fundamentar normas ou deduções a partir de normas, que, por seu turno, então, fossem diretamente aplicáveis. ${ }^{64}$ As reflexões de Sieckmann vão na mesma direção, para quem "a caracterização dos princípios como fundamentos para decisões de ponderação" serve de "ideia condutora" 65 .

Com esta orientação teórico-argumentativa, a teoria dos princípios se reaproxima de seu contexto de surgimento, a teoria da aplicação jurídica. Esser, Dworkin e outros pontuaram com razão que os princípios podem desempenhar um papel significativo na aplicação jurídica, em especial em casos difíceis, nos quais a aplicação não ocorre, como nos casos fáceis, mediante subsunção por meio de um simples seguir a regra. Esses conhecimentos, que são pouco discutíveis, foram radicalizados de um modo esplêndido pela teoria dos princípios, na formatação que ela recebeu a partir de Alexy e de seus alunos.

Como contribuição para uma teoria da argumentação, tal radicalização se relaciona primeiramente com a estrutura dos princípios jurídicos que são utilizados na aplicação.

\footnotetext{
${ }^{64}$ ESSER. Grundsatz und Norm in der richterlichen Form des Privatrechts. p. 137.

65 SIECKMANN. Regelmodelle und Prinzipienmodelle des Rechtssystems. p. 52; do mesmo autor comparar SIECKMANN. Rechtssystem und praktische Vernunft. p. 145-155 e ss.; da mesma forma, NEUMANN, U. Die Geltung von Regeln, Prinzipien und Elementen, (In) SCHILCHER, B.; KOLLER, P.; FUNK, B.-C. Regeln, Prinzipien und Elemente im System des Rechts. Wien: Österreich, 2000. p. 115-116 e ss., vê a função essencial dos princípios no nível da fundamentação de decisões jurídicas.
}

Cadernos do Programa de Pós-Graduação em Direito PPGDir./UFRgS | Edição Digital | Porto Alegre | Volume X | Número 3 | 2015 | P. $3-38$ 


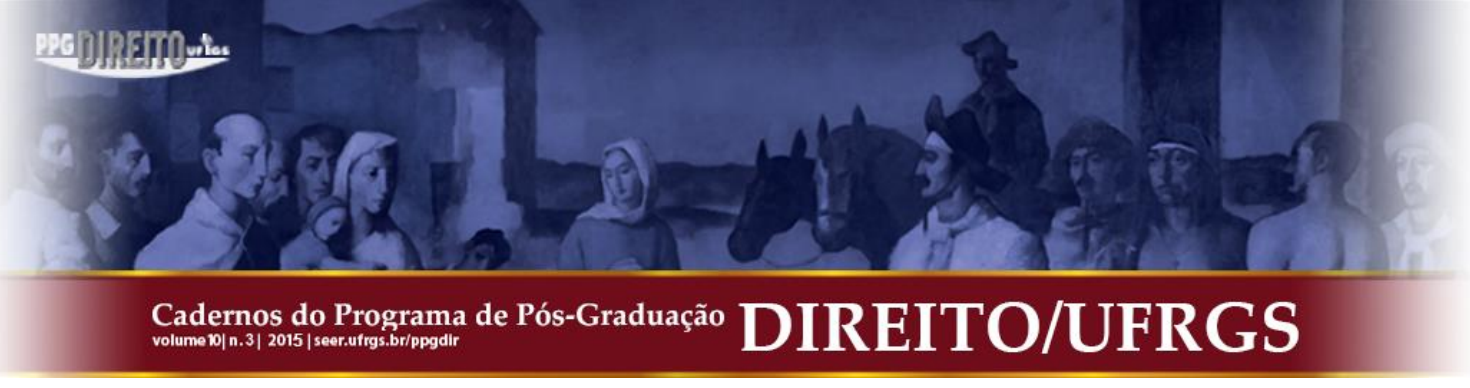

Segundo a teoria dos princípios, todos os princípios jurídicos que não possam ser aplicados sempre mediante um simples seguir a regra, devem ter a estrutura de mandamentos de otimização. Esta homogeneização dos princípios jurídicos, entretanto, tangencia sua diversidade. ${ }^{66}$

É de fato correto que alguns princípios jurídicos, como o princípio da proteção da confiança, sob certas circunstâncias, também podem ser reconstruídos como mandamentos de otimização. Mas isto não vale para todos os princípios jurídicos. Nossa ordem jurídica conhece uma gama inteira de princípios jurídicos que não apresentam a estrutura de otimização, sem decorrer desta inequivocidade, que eles possam ser aplicados sempre mediante um simples seguir a regra. Isto vale para um dos princípios jurídicos mais proeminentes, não apenas do Direito civil. O princípio da "boa-fé" (Treu und Glauben) não exige otimização, mas mera observação: Quando algo fere a boa-fé então não há que se falar mais em ponderação. ${ }^{67}$ Também o princípio da igualdade, com sua perspectiva fenomenológica comparativa, não pode ser colocado no espartilho de um mandamento de otimização, sem que exatamente este seu elemento específico se perca. ${ }^{68}$ Não por último, a diversidade dos princípios jurídicos se mostra também no princípio da proporcionalidade, que segundo a teoria dos princípios, está mais proximamente vinculado ao pensamento do mandamento de otimização: "a teoria dos princípios implica o princípio da proporcionalidade e vice-versa". ${ }^{69}$ Da mesma forma, entretanto, o princípio da proporcionalidade não precisa ser compreendido como mandamento de otimização. Já restou assinalado que, para além do critério pareto-otimal da necessidade, ele também pode ser compreendido como garantia de uma posição mínima ${ }^{70}$ ou como proibição de desproporcionalidade grave ${ }^{71}$. Os princípios constitucionais são compreendidos em geral por um grande número de autores como

\footnotetext{
${ }^{66}$ Isso vale também para a riqueza de facetas e significados que corresponde ao conceito de "princípio" na tradição filosófica, que tem na "Arché" grega um de seus pontos de partida conceituais. Para uma notável história do conceito REIMER. Verfassungsprinzipien, p. 146-171, que já por razões de história conceitual rejeita a redução do conceito de princípio a uma "aptidão para ponderação". Idem, p. 179.

67 Para esta objeção, com mais exemplos, também WEINBERGER, O. Revision des traditionellen Rechtssatzkonzepts. (In) SCHILCHER, B.; KOLLER, P.; FUNK, B.-C. Regeln, Prinzipien und Elemente im System des Rechts. Wien: Österreich, 2000.p. 53-64.

${ }^{68}$ Comparar para tal, SOMEK, A. Eine egalitäre Alternative zur Güterabwägung. (In) SCHILCHER, B.; KOLLER, P.; FUNK, B.-C. Regeln, Prinzipien und Elemente im System des Rechts. Wien: Österreich, 2000. p. 193-220.

${ }^{69}$ ALEXY. Zur Struktur von Rechtsprinzipien. p. 31/35.

${ }^{70}$ SCHLINK. Abwägung im Verfassungsrecht. p. 76-78, 192-195.

${ }^{71}$ PIEROTH, B.; SCHLINK, B. Grundrechte. nota lateral 294; POSCHER, R. Grundrechte als Abwehrrechte. p. 224.
}

Cadernos do Programa de Pós-Graduação em Direito PPGDir./UFRgS | Edição Digital | Porto Alegre | Volume X | Número 3 | 2015 | P. 3 - 38 


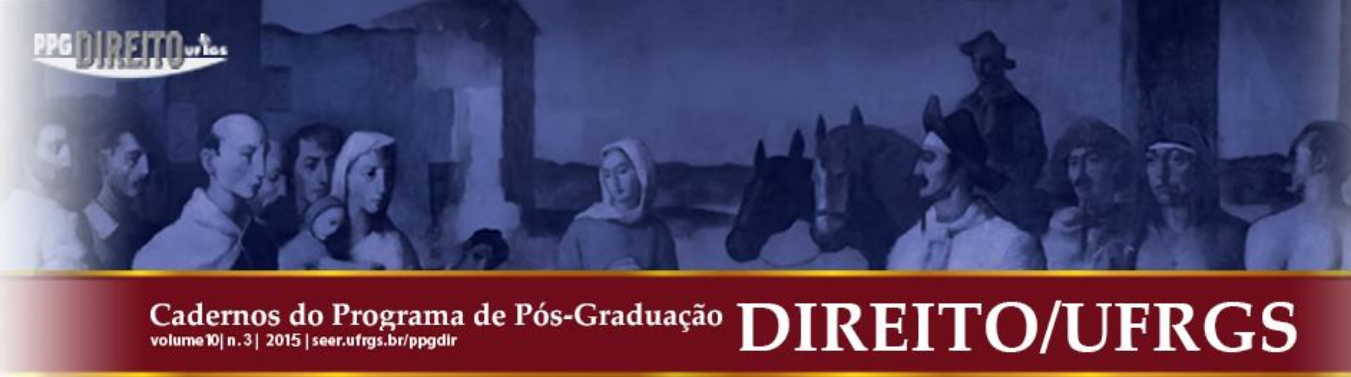

garantias-quadro ou garantias mínimas e não como mandamentos de otimização. ${ }^{72}$ Seja como for a atual interpretação destas controversas, elas de todo modo mostram que o princípio da proporcionalidade, em si, não precisa ser interpretado como mandamento de otimização. O processo de aplicação jurídica da ponderação otimizadora está em uma posição oblíqua (quer liegen $z u$ ) em relação ao conceito de princípio. É possível que haja princípios que podem ser aplicados pela via de uma ponderação otimizadora, mas inexiste qualquer conexão conceitual entre ponderação otimizadora e os princípios jurídicos. Ao contrário, uma correspondente moldagem de um princípio jurídico deve em primeiro lugar ser demonstrada interpretativamente. Especialmente para princípios constitucionais estas respectivas interpretações estão geralmente em concorrência com interpretações alternativas. No âmbito dessa concorrência elas não conseguem se impor por meio da referência a um caráter geral de otimização dos princípios.

Sem embargo, a pretensão teórico-argumentativa da teoria dos princípios não se esgota na tese da homogeneização. A partir de uma leitura extremamente geral ela objetiva não apenas a reconstrução dos princípios jurídicos tradicionais como mandamento de otimização, mas também a reconstrução da argumentação prática totalmente baseada no esquema de explicação dos mandamentos de otimização e da lei da ponderação. A teoria dos princípios não pretende, neste sentido, oferecer a única teoria da argumentação prática imaginável, mas sim a teoria superior. ${ }^{73}$ Nesta versão teórico-argumentativa da teoria dos princípios não se trata mais apenas de uma teoria especificamente jurídica, mas sim de uma teoria universal da argumentação prática, que pretende ter descoberto com a lei da ponderação a fórmula teóricoargumentativa mundial para o discurso prático.

Para essa versão teórico-argumentativa geral da teoria dos princípios todos os argumentos, inclusive aqueles cuja estrutura superficial não remete a um mandamento de otimização, devem, em última instancia, poder ser reconduzidos a mandamentos de otimização. Em uma controvérsia acerca do dever dos motociclistas usarem capacete o argumento do direito de autodeterminação poderia então ser construído diretamente como

\footnotetext{
${ }^{72}$ HAIN, K-E. Die Grundsätze des Grundgesetzes. p. 157; REIMER, F. Verfassungsprinzipien. p. 329-333, 338348, respectivamente com mais notas.

${ }^{73}$ SIECKMANN. Rechtssystem und praktische Vernunft. p. 155 e ss.; neste mesmo volume, JANSEN, Nils. Die normativen Grundlagen rationalen Abwägens., parte, em todo caso, de uma superioridade normativa da teoria dos princípios.
}

Cadernos do Programa de Pós-Graduação em Direito PPGDir./UFRGS | Edição Digital | Porto Alegre | Volume X | Número 3 | 2015 | P. 3 - 38 


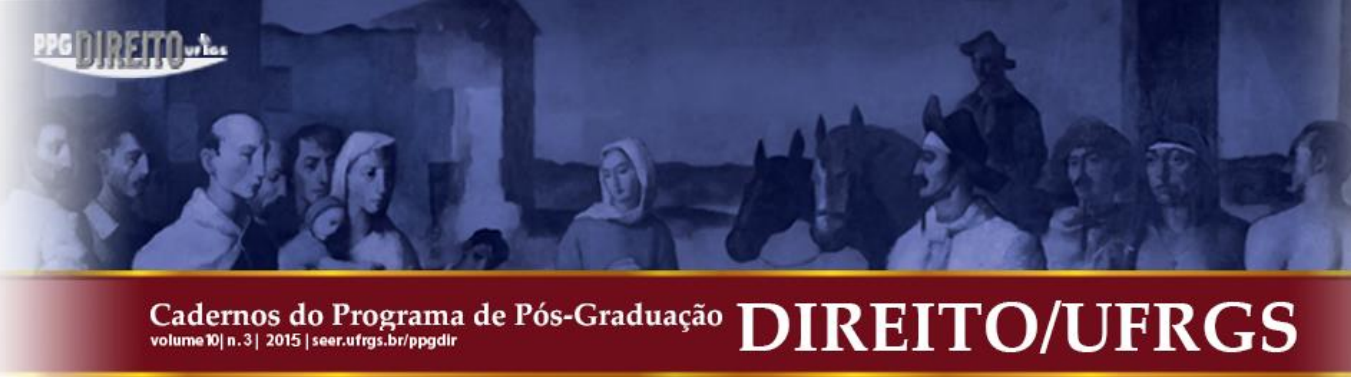

mandamento de otimização ${ }^{74}$. Entretanto, o mesmo se aplicaria também para o argumento contrário da previsibilidade do aumento de mortes no trânsito, que, enquanto prognose sobre fatos, não possui o caráter de um mandamento de otimização. Nesta medida, os defensores da teoria dos princípios podem fazer referência ao caráter entimemático ${ }^{75}$ dos argumentos fáticos no discurso prático. Segundo o princípio da universabilidade de Richard M. Hare, um argumento moral somente é então completo, se uma norma puder ser especificada com critérios tais que permitam que fatos mencionados sejam caracterizados como normativos. ${ }^{76}$ Para os defensores da teoria dos princípios isto significa que o argumento das mortes no transito deve ser reconduzido a um mandamento de otimização. No exemplo, reconduzido ao mandamento para otimizar a proteção da vida, tendo em conta as condições fáticas e jurídicas. Depois da recondução correspondente de todos os argumentos ao mandamento de otimização, todas as questões práticas devem ser decididas por meio da lei da ponderação.

Entretanto, do princípio da Universalidade proposto por Hare apenas resulta que argumentos fáticos devam ser reconduzidos a normas, mas nada acerca do conteúdo das respectivas normas ${ }^{77} \mathrm{e}$, com isso, também não resulta que elas devam um mandamento de otimização como conteúdo. Assim, por exemplo, o mandamento de evitar sofrimento que está na base das argumentações práticas de Stephen E. Toulmin ${ }^{78}$ não possui como conteúdo um mandamento de otimização. Em virtude disso, a tese teórico-argumentativa geral da teoria dos princípios somente se sustentaria se as normas que não tem um mandamento de otimização como conteúdo pudessem novamente ser reconduzidas a mandamentos de otimizações e sua ponderação. Entretanto, o catálogo de normas, não apenas formais, mas também materiais ${ }^{79}$, que o próprio Alexy desenvolveu para argumentação prática e para o qual a teoria dos princípios sempre novamente apela, ${ }^{80}$ não é corolário de nenhuma ponderação de princípios, mas sim essencialmente de reflexões (linguístico-)analíticas bem como pragmático-universais e/ou pragmático-transcendentais. Além disso, também não é evidente para a argumentação prática em geral, que nela, em última instância, normas que estabeleçam posições mínimas,

\footnotetext{
${ }^{74}$ Para uma construção como esta, ver FISCHER, K. Die Zulässigkeit aufgedrängten staatlichen Schutzes vor Selbstschädigung. 1997, p. 132-165.

75 Acerca disso, FOLLESDAL, D./ WALlOE, L / ESTER, J. Rationale Argumentation. Berlin: Walter de Gruyter \& Co (1977), 1988. p. 244 e ss.

${ }^{76}$ HARE, R. M. Freiheit und Vernunft. Frankfurt: Suhrkamp, 1973. p. 105-248.

${ }^{77}$ ALEXY, R. Theorie der juristischen Argumentation. Frankfurt: Suhrkamp, 1983.

78 TOULMIN, S. E. The Place of Reason in Ethics. London: Cambridge University Press, 1950. p. 136, 223.

${ }^{79}$ Comparar, em Alexy, a Regra 2.3: ALEXY, R. Theorie der juristischen Argumentation. p. 240.

${ }^{80}$ Por todos, ALEXY, R. Theorie der Grundrechte. p. 498-521. 


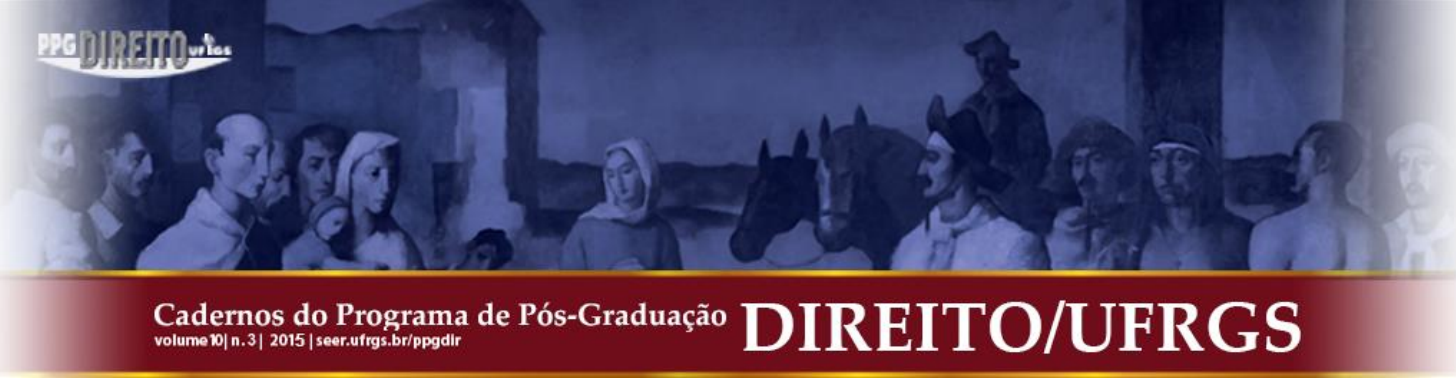

que exijam reflexões sobre desproporcionalidade excessiva ou disponham sobre exigências de tratamento igualitário etc. e que não possam ser reconstruídas como ou reconduzidas a mandamentos de otimização, certamente não com um ganho sistemático ou teórico, não exerçam uma função. ${ }^{81}$ Se por exemplo normas não sujeitas a ponderação fossem redefinidas como princípios absolutos, cujo peso fosse tão forte que eles se impusessem em qualquer ponderação, ${ }^{82}$ esta redefinição contribuiria para imunização da teoria dos princípios para o seu próprio bem, mas não para o conhecimento. Também não é evidente qual a vantagem que a ponderação de princípios deveria ter em relação a outras fontes de conhecimento prático como, por exemplo, nossas intuições, uma vez que ela mesma, no entanto, se baseia em intuições dificilmente explicáveis acerca do peso relativo dos princípios em ponderação. ${ }^{83}$ Para a argumentação jurídica acresce ainda, que, no Direito, frequentemente as otimizações já estão pré-estruturadas pelo legislador, e não podem mais ser colocadas em questão por meio de uma ponderação. A teoria dos princípios tenta dar conta deste argumento dizendo que ela reinterpreta a vinculação à legislação também como um mandamento de otimização, ordenado estruturalmente de forma equivalente a outros princípios. ${ }^{84}$ Mas a aplicação jurídica será caracterizada erroneamente se, em última análise, todas as disposições de direito positivo forem reduzidas a um mandamento pressuposto no sentido de otimizar a vinculação à legislação, que deve respectivamente ser ponderado com todos os outros pontos de vista abordados no caso concreto.

Contudo, uma descrição precisa do papel dos princípios jurídicos e, entre eles, também dos que contêm otimizações como conteúdo, bem como da lógica interna da ponderação

\footnotetext{
${ }^{81}$ Para outros processos argumentativos alternativos também JANSEN. Die normativen Grundlagen rationalen Abwägens.

82 SIECKMANN. Regelmodelle und Prinzipienmodelle des Rechtssystems. p. 59; do mesmo, SIECKMANN. Rechtssystem und praktische Vernunft. p. 156; de forma mais cautelosa, ALEXY, R. Theorie der Grundrechte. p. 156.

83 SOMEK, A. Abwägungsregeln. (In) HIEBAUM, C.; KOLLER, P. (Org.) Politische Ziele und juristische Argumentation. ARSP-Beihcft 92. Stuttgart: Franz Steiner, 2003. p. 113 e ss.

84 Acerca dos princípios formais ver ALEXY, R. Theorie der Grundrechte. p. 120; SIECKMANN. Regelmodelle und Prinzipienmodelle des Rechtssystems. p. 147-164; em especial para a reconstrução da prerrogativa de decisão do legislador com base em princípios formais, RAABE. Grundrechte und Erkenntnis. Baden-Baden: Nomos, 1998.; criticamente em relação à adequação dos princípios formais para redução de falhas de competências e da perda de determinação que surgem a partir da interpretação teórico-principiológica do Direito, HAIN. Die Grundsätze des Grundgesetzes. p. 135-138; no mesmo sentido, detalhadamente com vistas aos espaços de atuação política do legislador, M. JESTAEDT. Grundrechtsentfaltung im Gesetz. Tübingen: Mohr Siebeck, 1999. p. 222-260; POSCHER. Grundrechte als Abwehrrechte. p. 82-84 respectivamente com fontes adicionais. A remissão obrigatória ao discurso prático geral para superação desta indeterminação induzida pela teoria dos princípios se expõe à contradição que ALEXY. Theorie der juristischen Argumentation, p. 355, procura evitar com fundamento nas restrições que o discurso jurídico impõe ao discurso geral. Sobre isso ver também HAIN. Die Grundsätze des Grundgesetzes. p. 141-157.
} 


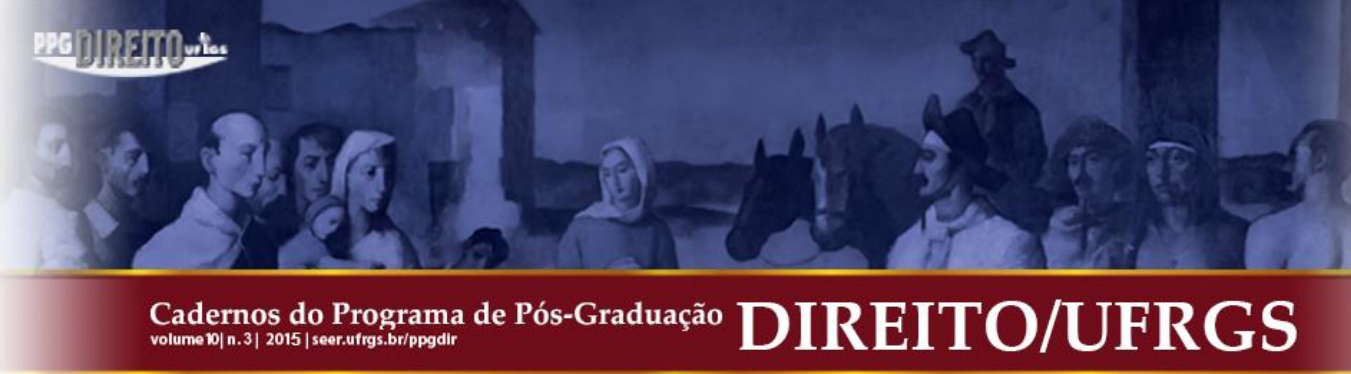

otimizadora no âmbito de uma reconstrução abrangente dos diferentes processos de aplicação jurídica, poderia consistir em um mérito de uma teoria dos princípios. A teoria dos princípios encontraria sua determinação sistemática como parte de uma teoria da aplicação jurídica prática que, por sua vez, é parte de uma teoria abrangente da aplicação do Direito. Diferentemente do que pensam seus defensores, o ganho não residiria em uma "simplificação essencial em nossa compreensão acerca do papel da aplicação jurídica" ${ }^{\text {, }}$, que reduz a aplicação jurídica à ponderação de interesses quando não se está diante de casos fáceis. ${ }^{86} \mathrm{Na}$ medida em que a teoria dos princípios reduz a configuração multifacetada da aplicação jurídica à alternativa "subsunção ou ponderação", ela dá um passo atrás, enquanto teoria da argumentação, em relação ao nível de conhecimento já atingido, para o qual de forma mais intrincada o próprio Alexy competentemente contribuiu. ${ }^{87}$ Simplificação no sentido de sua teoria dos princípios significaria, em contrapartida, uma perda da capacidade de diferenciar e de profundidade da nossa compreensão acerca daquilo que nós fazemos quando aplicamos Direito.

Direitos fundamentais também podem ser argumentos no sentido de apoiar juízos de valor em argumentações jurídicas, que, pressupõem, por exemplo, que a liberdade de imprensa enquanto tal é desejável e não um mal. Alguém que em uma argumentação jurídica sustente, que uma determinada aplicação de uma norma promove a liberdade de imprensa, sem ameaçar outros bens jurídicos, tem um argumento, uma vez que a liberdade de imprensa foi reconhecida positiva e normativamente em um artigo da Lei Fundamental. Também de uma teoria dos princípios assim orientada para uma teoria da argumentação não decorre, no entanto, que o conteúdo dos direitos fundamentais se limite a este significado reconstruído argumentativamente nos moldes teórico-principialistas. Ali onde os direitos fundamentais são utilizados não somente para apoio normativo de um argumento, mas como medida para limitações concretas, eles podem ser desdobrar nitidamente em formas dogmáticas mais exigentes. $^{88}$

\footnotetext{
${ }^{85}$ KOCH, H.-J. Rechtsprinzipien im Bauplanungsrecht. (In) SCHILCHER, B.; KOLLER, P.; FUNK, B.-C. (Org.) Regeln, Prinzipien und Elemente im System des Rechts. Wien: Österreich, 2000. p. 245-257.

${ }^{86}$ Koch parece, nesta medida, sucumbir a uma ameaça para a qual ele mesmo adverte em outro momento: "O papel dos princípios [..] na solução de casos difíceis não deveria de forma alguma ser sobrestimado [...] em uma espécie de embriaguez principiológica.” KOCH, H.-J. Zur Methodenlehre des Rechtspositivismus. p. 152-160.

${ }^{87}$ ALEXY. Theorie der juristischen Argumentation.

${ }^{88}$ Inexiste escassez de propostas correspondentes. Para tal, ver em BUMKE, C. Der Grundrechtsvorbehalt. Baden-Baden: Nomos, 1998., uma proposta funcional pluralista e em POSCHER. Grundrechte als Abwehrrechte., uma proposta funcional monista.
} 


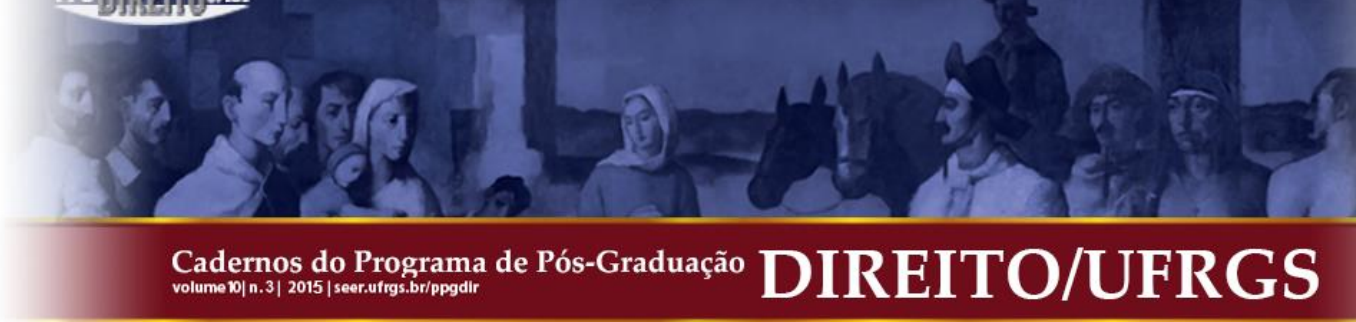

\section{O EQUÍVOCO DE AUTOCOMPREENSÃO: A TEORIA DOS PRINCÍPIOS COMO DOGMÁTICA}

O giro teórico-argumentavivo da teoria dos princípios já demonstra onde reside fundamentalmente o seu equívoco de autocompreensão como teoria dos direitos fundamentais. Se há um mérito na teoria dos princípios então ele reside no âmbito e no nível de abstração, no qual ela originariamente surgiu neste e naquele lado do Attântico. A teoria dos princípios se movimenta no nível da teoria geral da aplicação jurídica, da teoria da argumentação jurídica. Isso sempre esteve, de qualquer forma, claro para Esser e caracterizava para ele exatamente o essencial dos princípios jurídicos. ${ }^{89} \mathrm{O}$ significado dos princípios não consiste em substituir a dogmática, mas sim em esclarecer seu surgimento e sua necessidade. Nesta linha pensava Esser acerca do princípio do enriquecimento ilícito, ao qual ele sempre fazia referência como um caso arquetípico de princípio:

Assim, a fim de que possamos de uma maneira geral ter alguma ideia acerca deste
princípio "material", é necessária a fixação de todos os elementos dogmáticos do
Direito dos contratos e do Direito ao enriquecimento ilícito e da construção de
ambas as instituições por forca da tradição jurisprudencial e doutrinária. ${ }^{90}$

A colocação da ponderação de princípios e da dogmática no mesmo nível se equivoca, em primeiro lugar, quanto à função argumentação jurídica e, com isso, também com relação à função que os princípios tem neste mesmo espaço, qual seja, a de fundamentar as dogmáticas; em segundo lugar, uma dogmática que se limite à ponderação de princípios não pode ser assim considerada. A dogmática surge por meio da formação de estruturas normativas no caminho da argumentação jurídica na qual, ao lado de casos julgados, tradições, história, gênese, circunstâncias fáticas, reflexões analíticas e sistemáticas etc., podem entrar também ponderações otimizadoras. Mas ponderação de princípios não é dogmática. Ela oferece apenas uma estrutura argumentativa dentre outras, no interior da qual se pode argumentar acerca de uma determinada dogmática dos direitos fundamentais. ${ }^{91}$

\footnotetext{
${ }^{89}$ ESSER. Grundsatz und Norm in der richterlichen Form des Privatrechts. p. 79 e ss.

${ }^{90}$ ESSER. Grundsatz und Norm in der richterlichen Form des Privatrechts. p. 154.

${ }^{91}$ Assim também CREMER, W. Freiheitsgrundrechte. Tübingen: Mohr Siebeck, 2003. p. 223-227. 


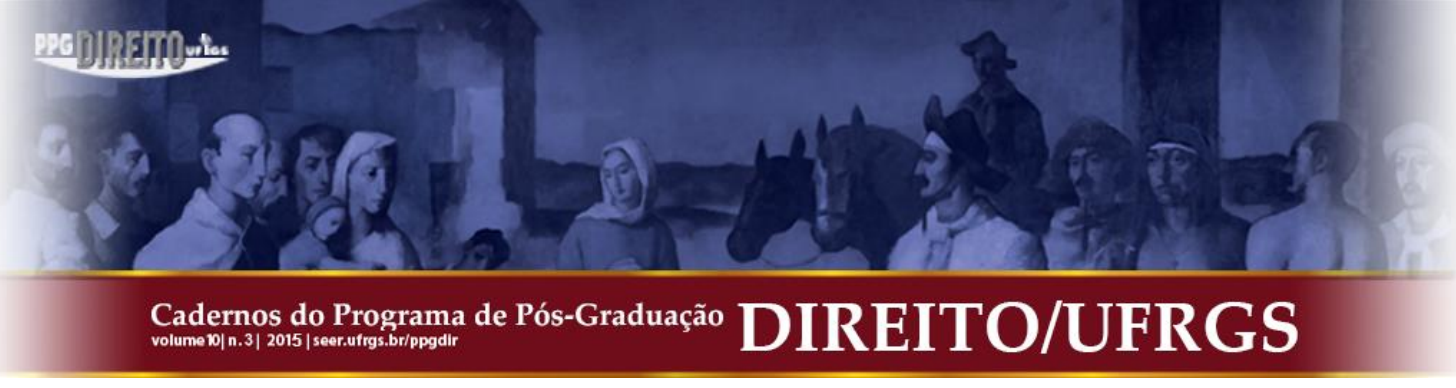

Isso não significa que esforços dogmáticos não possam falhar. ${ }^{92}$ Se se quer demonstrar que as normas de direitos fundamentais existentes não autorizam uma estruturação mais forte, para além de remeter ao fato de que, observando-se todas as circunstancias do caso concreto, os direitos fundamentais em colisão devam ser ponderados, ${ }^{93}$ então este poderia também ser o resultado de uma discussão dogmática com os direitos fundamentais. Mas a interpretação de uma estrutura normativa que apenas diga que o aplicador do direito deva chegar a uma ponderação fundamentada racionalmente, ${ }^{94}$ observando todas as circunstancias do caso concreto, é o ponto zero de uma dogmática jurídica. Não é capaz exatamente de desenvolver proposições dogmáticas concretizadoras com ajuda da argumentação jurídica. Qualquer outra sugestão que não esteja em posição de inferioridade em algum outro aspecto em relação a essa teoria, seria preferível sob todos os critérios que são listados para a eficiência de uma dogmática jurídica, isto é, função de orientação, capacidade de ensinar e aprender, potencial crítico para decisões etc. ${ }^{95}$ De qualquer forma, esta capitulação da dogmática dos direitos fundamentais não está prefigurada pela estrutura lógica dos direitos fundamentais nem por meio de conhecimentos metodológicos para a aplicação jurídica.

Se a garantia da dignidade da pessoa humana deveria ser entendida como absoluta, não sujeita à ponderação, ou como um mandamento de otimização conduzido via ponderação, ${ }^{96}$ não é uma questão de lógica jurídica ou de metodologia, mas uma decisão dogmática, sobre a qual é possível discutir com todos os meios da argumentação jurídica. Um destes meios é certamente a ponderação de uma grande quantidade de argumentos. O mesmo se aplica à decisão sobre se o conceito de "lei geral" contido no art. 5, inciso 2 da Lei Fundamental deve ser compreendido no sentido de uma teoria da ponderação ou de uma teoria do direito especial (Sonderrechtslehre), que não pode ser tomada com base em um suposto caráter de princípio dos direitos fundamentais, que a abre regra geral para ponderação. Também em favor da

\footnotetext{
92 O Direito positivo pode exigir, como na Lei do Plano Diretor (Planungsrecht), uma ponderação explícita que, em certas circunstâncias, pode ser reconstruída mais adequadamente como mandamento de otimização. Acerca do Plano Diretor, ver KOCH. Rechtsprinzipien im Bauplanungsrecht.

93 Sensível a esta tendência da teoria dos princípios para uma "jurisdição ad hoc" (Kadijustiz), KOCH. Die normtheoretische Basis der Abwägung. p. 9-19.

${ }^{94}$ Suscintamente ROSSEN, H. Grundrechte als Regeln und Prinzipien (In) GRABENWARTER, C. et. ali. (Org.) Allgemeinheit der Grundrechte und Vielfalt der Gesellschaft. Ed. C. Grabenwarter et al. Stuttgart: Boorberg. 1994. p. 42-59: "Que de uma norma decorre um juízo singular que decide o caso exige, antes, uma justificação separada [...] que somente é imparcial se considerar por completo todos os elementos fáticos e jurídicos do caso concreto."

95 ALEXY. Theorie der juristischen Argumentation. p. 326.

${ }^{96}$ Quanto a isto, do ponto de vista da teoria dos princípios, TEIJKE. Flexibilität der Menschenwürde? p. $142-$ 156.
}

Cadernos do Programa de Pós-Graduação em Direito PPGDir./UFRgS | Edição Digital | Porto Alegre | Volume X | Número 3 | 2015 | P. 3 - 38 


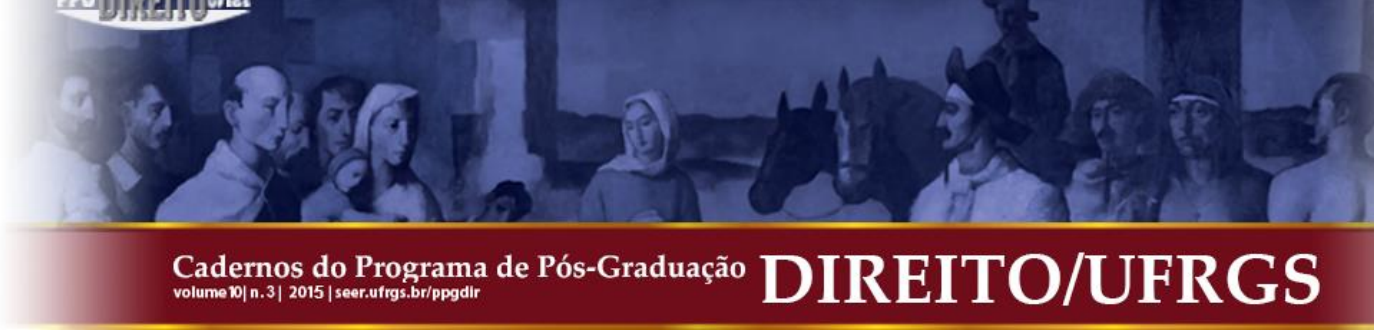

ADICKES, F. Zur Lehre von den Rechtsquellen insbesondere über die Vernunft und die Natur der sache als Rechtsquellen und über das Gewohnheitsrecht. Kassel: Wigand, 1872.

ALEXY, R. Begriff und Geltung des Rechts. Freiburg: Alber, 1992.

. On Balancing and Subsumption. (In) Ratio Juris 16, 2003.

. Theorie der Grundrechte. Frankfurt: Suhrkamp, 1986.

. Theorie der juristischen Argumentation. Frankfurt: Suhrkamp, 1983.

. Zum Begriff des Rechtsprinzips. (In) ALEXY, R. Rechts, Vernunft, Diskurs. Frankfurt: Suhrkamp, 1995.

Zur Struktur von Rechtsprinzipien. (In) SCHILCHER, B.; KOLLER, P.; FUNK,

B.-C. (Org.) Regeln, Prinzipien und Elemente im System des Rechts. Wien: Österreich, 2000.

BAYLES, M. D. Principles of Law. A normativ analisys. Dordrecht: Reidel, 1987.

BOROWSKI, Martin. Grundrechte als Prinzipien. 2. Auflage. Baden-Baden: Nomos, 1998.

Mohr Siebeck, 2006.

Die Glaubes-und Geewissenfreiheit des Grundgesetzes. Tübingen:

Prinzipien als Grundrechtsnormen. (In) ZöR 53: 1998.

BÜLOW, O. Gesetz und Richteramt. Berlin: Berliner Wissenschaftsverlag, 1885.

BUMKE, C. Der Grundrechtsvorbehalt. Baden-Baden: Nomos, 1998.

BVerfG, NJW 2006, 751/757.

BVerfG. NJW 2001, 2075. 
BVerfG, NJW 2006, 751-761.

BVerfGE 27. I (6).

BVerfGE 111, 147.

COLEMAN, J L. The Practice of Principle. Oxford: Oxford University Press, 2001.

CREMER, W. Freiheitsgrundrechte. Tübingen: Mohr Siebeck, 2003.

DUXBURY, N. Jhering's Philosophy of Authority. Oxford Journal of Legal Studies: 2007.

Patterns of American Jurisprudence. Oxford: Oxford University Press: 1995.

DWORKIN, R. Bürgerrechte ernstgenommen. Frankfurt: Suhrkamp, 1984.

. Law's Empire. Cambridge: Harvard University Press, 1986.

EHRLICH, E. Freie Rechtsfindung und freie Rechtswissenschaft. Leipzig: C. L. Hirschfeld, 1903.

Humblot, 1913.

Grundlegung der Soziologie des Rechts. München und Leipzig: Duncker und .̈̈ber Lücken im Rechte. (1888), in: EHRLICH, E. Recht und Leben. Berlin: Duncker und Humblot, 1967.

ESSER, J. Grundsatz und Norm in der richterlichen Form des Privatrechts. 4. ed. Tübingen: Mohr Siebeck, 1990.

FOLLESDAL, D.; WALLOE, L.; ESTER, J. Rationale Argumentation. Berlin: Walter de Gruyter \& Co (1977), 1988. 


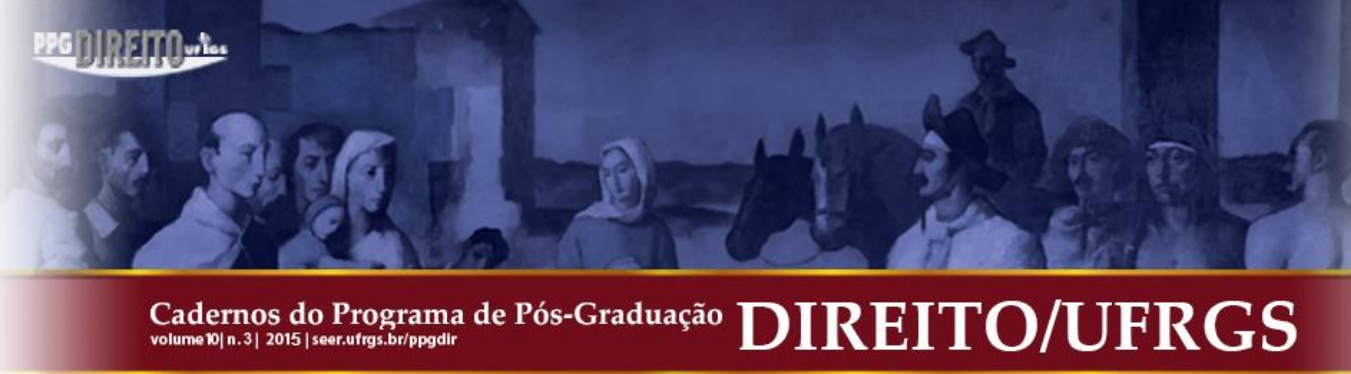

Zur Methodenlehre des Rechtspositivismus. (In) DREIER, R. (Org.), Rechtspositivismus und Wertbezug des Rechts. ARSP Beiheft 37: 1988.

. Rechtsprinzipien im Bauplanungsrecht. (In) SCHILCHER, B.; KOLLER, P.; FUNK, B.-C. (Org.) Regeln, Prinzipien und Elemente im System des Rechts. Wien: Österreich, 2000.

LARENZ, K. Methodenlehre der Rechtswissenschaft. 6. ed. Berlin: Springer, 1991.

LEITER, B. American Legal Realism. (In) EDMUNDSON, W.; GOLDING, M (Org.) The Blackwell Guide to Philosophy of Law and Legal Theory. Malden: Wiley-Blackwell, 2003.

LERCHE, P. Übermaß und Verfassungsrecht. 2. ed. Goldbach: Keip,1999.

LLEWELLYN, K. N. A Realistic Jurisprudence - The Next Step. (In) Columbia Law Review $30,1930$.

MARMOUR, A. The Separation Thesis and the Limits of Interpretation. Can. J.L.\& Juris. 12, 1999.

MICHAEL, L. Methodenfragen der Abwägungslehre, (In) Jahrbuch des offentlichen Rechts der Gegenwart 48: 2000.

NELKEN, D. Pound and Ehrlich on the Living Law. (In) Rechtstheorie, 1986.

NEUMANN, U. Die Geltung von Regeln, Prinzipien und Elementen. (In) SCHILCHER, B.; KOLLER, P.; FUNK, B.-C. (Org.) Regeln, Prinzipien und Elemente im System des Rechts. Wien: Österreich, 2000.

OGOREK, R. Richterkönig oder Subsumtionsautomat? Frankfurt: Klostermann, 1986.

PASCUA, J. A. R. Die Grundlage der rechtlichen Geltung von Prinzipien (In) ORSI, G. Prinzipien des Rechts. Frankfurt: Peterlang, 1996.

PIEROTH, B.; SCHLINK, B. Grundrechte. 21. ed. Heidelberg: C.F. Müller, 2005. 


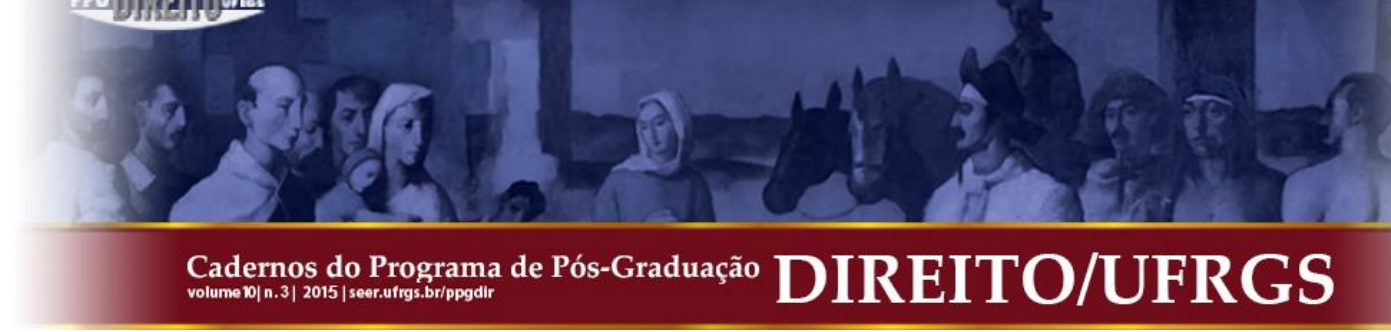

POSCHER, R. Grundrechte als Abwehrrechte. Tübingen: Mohr Siebeck, 2003.

POUND, R. An Introduction to the Philosphy of Law. 24. ed. Cumberland, RI: Yale University Press, 1982.

Enforcement of Law. Washington: Green Bag, 1908.

. Law in Books and Law in Action. Am. L. Rev. 44, 1910.

PRIEL, D. Farewell to the Exclusive-Inclusive Debate. Oxford Journal of Legal Studies 25: 2005.

RAABE, M. Grundrechte und Erkenntnis. Baden-Baden: Nomos, 1998.

RAZ, J. Legal principles and the Limits of the Law. The Yale Law Journal 81, 1972.

REIMER, F. Verfassungsprinzipien. Berlin: Duncker \& Humblot, 2001.

ROSSEN, H. Grundrechte als Regeln und Prinzipien (In) GRABENWARTER, C. et. al. (Org.) Allgemeinheit der Grundrechte und Vielfalt der Gesellschaft. Ed. C. Grabenwarter et al. Stuttgart: Boorberg. 1994.

SCHILCHER, B. Prinzipien und Regeln als Elemente einer Theorie des gebundenen Ermessens. (In) SCHILCHER, B.; KOLLER, P.; FUNK, B.-C. (Org.) Regeln, Prinzipien und Elemente im System des Rechts. Wien: Österreich, 2000.

SCHILCHER, B.; KOLLER, P.; FUNK, B.-C. (Org.) Regeln, Prinzipien und Elemente im System des Rechts. Wien: Österreich, 2000.

SCHLINK, B. Abwägung im Verfassungsrecht. Berlin: Duncker \& Humblot, 1976.

SIECKMANN, J.-R. Modelle des Eigentumsschutzes. Baden-Baden: Nomos, 1998. 


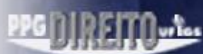

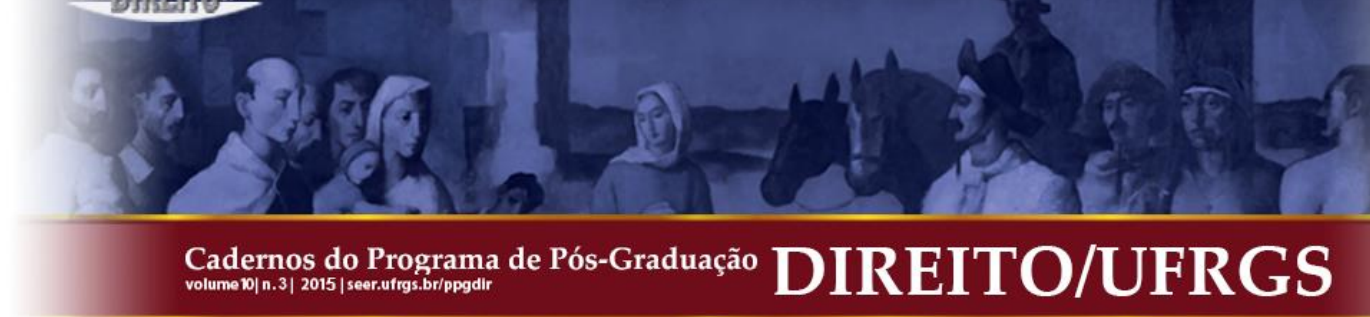

Sozialphilosophie 78: 1992.

Rechtssystem und praktische Vernunft (In) Archiv für Rechts- und Nomos, 1990

Regelmodelle und Prinzipienmodelle des Rechtssystems. Baden-Baden:

Zur Analyse von Normkonflikten und Normabwägungen. (In) MEGGLE,

G. Analyomen, 2. Proceedings of the 2nd Conference "Perspectives in Analytical Philosophy", Bd. III. Berlin: de Gruyter, 1994.

SOMEK, A. Abwägungsregeln. (In) HIEBAUM, C.; KOLLER, P. (Org.) Politische Ziele und juristische Argumentation. ARSP-Beihcft 92. Stuttgart: Franz Steiner, 2003.

Eine egalitäre Alternative zur Güterabwägung. (In) SCHILCHER, B.; KOLLER, P.; FUNK, B.-C. (Org.) Regeln, Prinzipien und Elemente im System des Rechts. Wien: Österreich, 2000.

SUMMERS, R. S. Rudolf von Jhering's Influence on American Legal Theory. (In) BEHRENDS, O. (Org.), Jherings Rechtsdenken. Göttingen: Vandenhoeck \& Ruprecht, 1996.

TEIFKE, N. Flexibilität der Menschenwürde? (In) Bäcker, C.; Baufeld, S. (Org.), Objektivität und Flexibilität im Recht. ARSP Beiheft 103. Stuttgart: Franz Steiner, 2005.

TOULMIN, S. E. The Place of Reason in Ethics. London: Cambridge University Press, 1950.

VERHEIJ, B.; HAGE, J.; VAN DEN HERIK, H. J. An integrated view on rules and principles. Artificial Intelligence and Law 6. 1998.

WEINBERGER, O. Revision des traditionellen Rechtssatzkonzepts. (In) SCHILCHER, B.; KOLLER, P.; FUNK, B.-C. Regeln, Prinzipien und Elemente im System des Rechts. Wien: Österreich, 2000.

WITTGENSTEIN, L. Philosophische Untersuchungen. ANSCOMBE, G.E.M.; WRIGHT, G.H.; REES, Rush (Org.), (1953), (In) Werkausgabe, Vol. 1, 2. ed. 1992. 


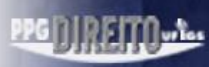

Cadernos do Programa de Pós-Graduação
volume $0 \mid$ n.3| 2015 |seer.utrgs.br/ppgdilr

Submissão: $18 / 12 / 2015$

Aceito para Publicação: 18/12/2015 
MaDIREM

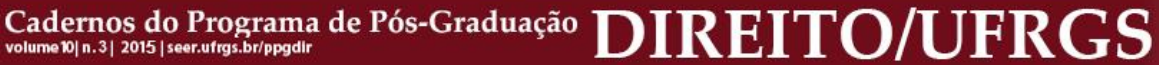

38 